\title{
1 Parallel genomics uncover novel enterococcal-bacteriophage interactions
}

2

3 Anushila Chatterjee ${ }^{a}$, Julia L. E. Willett ${ }^{b}$, Uyen Thy Nguyen ${ }^{c}$, Brendan Monogue ${ }^{a}$, Kelli L. Palmer ,

4 Gary M. Dunny ${ }^{\mathrm{b}}$, Breck A. Duerkop ${ }^{\mathrm{a}, \#}$

5

6 aDepartment of Immunology and Microbiology, University of Colorado School of Medicine, Aurora,

7 CO, USA, 80045. 'bepartment of Microbiology and Immunology, University of Minnesota Medical

8 School, Minneapolis, MN, USA, 55455. 'Department of Biological Sciences, University of Texas

9 at Dallas, Richardson, TX, USA, 75080.

10

$11 \quad$ \#Correspondence: Breck A. Duerkop breck.duerkop@cuanschutz.edu

12

13

14

15 Running title: Genomic analysis of E. faecalis-phage interaction

16

17 Key words: bacteriophages, Enterococcus, antibiotic resistance, transposons, RNAseq, TnSeq,

18 phage-bacteria interactions 


\section{Abstract}

Bacteriophages (phages) have been proposed as alternative therapeutics for the treatment of multidrug resistant bacterial infections. However, there are major gaps in our understanding of the molecular events in bacterial cells that control how bacteria respond to phage predation. Using the model organism Enterococcus faecalis, we employed two distinct genomic approaches, transposon (Tn) library screening and RNA sequencing, to investigate the interaction of $E$. faecalis with a virulent phage. We discovered that a transcription factor encoding a LytR family response regulator controls the expression of enterococcal polysaccharide antigen (epa) genes that are involved in phage infection and bacterial fitness. In addition, we discovered that DNA mismatch repair mutants rapidly evolve phage adsorption deficiencies, underpinning a molecular basis for epa mutation during phage infection. Transcriptomic profiling of phage infected $E$. faecalis revealed broad transcriptional changes influencing viral replication and progeny burst size. We also demonstrate that phage infection alters the expression of bacterial genes associated with intra and inter-bacterial interactions, including genes involved in quorum sensing and

41 polymicrobial competition. Together our results suggest that phage predation has the potential to

42 influence complex microbial behavior and may dictate how bacteria respond to external 43 environmental stimuli. These responses could have collateral effects (positive or negative) on 44 microbial communities such as the host microbiota during phage therapy.

We lack fundamental understanding of how phage infection influences bacterial gene expression and consequently how bacterial responses to phage infection affect the assembly of

49 polymicrobial communities. Using parallel genomic approaches, we have discovered novel 50 transcriptional regulators and metabolic genes that influence phage infection. The integration of 51 whole genome transcriptomic profiling during phage infection has revealed the differential 52 regulation of genes important for group behaviors and polymicrobial interactions. Our work 
53 suggests that therapeutic phages could more broadly influence bacterial community composition

54 outside of their intended host targets.

\section{Introduction}

Enterococcus faecalis is a member of the healthy human intestinal microbiota (1). E. faecalis

58 is also a pathobiont that rapidly outgrows upon antibiotic mediated intestinal dysbiosis to cause

59 disease. E. faecalis is associated with nosocomial sepsis, endocarditis, surgical-site, urinary tract

60 and mixed bacterial infections (2, 3). Since the 1980's, enterococci have been evolving extensive-

61 drug resistance, including resistance to vancomycin and "last-line-of-defense" antibiotics (4-10).

62 In addition, E. faecalis can disseminate antibiotic resistance traits to diverse bacteria including

63 other clinically relevant pathogens (11-17). There is an urgent need for new therapeutics that

64 target drug resistant enterococci.

65 Bacteriophages (phages) are viruses that infect bacteria. Phages are being considered for the

66 treatment of multi-drug resistant (MDR) bacterial infections, including enterococcal infections.

67 Recent studies have demonstrated the potential for phage-based therapies against systemic and

68 biofilm associated enterococcal infections (18-22). The decolonization of intestinal MDR E.

69 faecalis may be achieved through the action of phage predation which selects for cell wall variants

70 that are rendered sensitive to antibiotic therapy (23). However, a potential barrier to the wide-

71 spread use of phage therapy against E. faecalis is the development of phage resistance. To

72 confront this issue, we must understand the molecular mechanisms used by phages to infect $E$.

73 faecalis and how E. faecalis overcomes phage infection to become resistant. Only then can this

74 biology be exploited to better develop phage therapies that mitigate the risk of developing phage

75 resistance.

76 The study of phage-bacteria interactions has provided key insights into phage infection that

77 could lead to the development of novel antibacterial therapies. Phages replicate in bacteria by 
78 hijacking the host cellular machinery to produce phage progeny. To exploit host cell resources,

79 many phages encode auxiliary proteins which are not directly involved in phage genome

80 replication or particle assembly but can modulate bacterial physiology to favor phage propagation

$81(24,25)$. The characterization of phage auxiliary proteins may yield tools for curtailing bacterial

82 infections. Additionally, the discovery of phage-modulated host pathways could reveal potential

83 therapeutic targets. Our understanding of global bacterial cellular responses during phage

84 infection is limited to transcriptomic analyses in Gram-negative bacteria, whereas Gram-positive

85 species are understudied (26-31). Therefore, to fill this gap and further define the molecular

86 underpinnings of enterococcal-phage interactions, we have taken a global genomics approach to

87 identify enterococcal factors critical for productive infection by the lytic phage VPE25 (32). To

88 identify bacterial genes essential for VPE25 infection, we screened a low-complexity transposon

89 (Tn) mutant library of $E$. faecalis OG1RF for phage resistance (33). In addition to the known

90 VPE25 receptor (32), transposon sequencing revealed novel $E$. faecalis genes necessary for

91 phage adsorption and optimum intracellular phage DNA replication and transcription. To gain

92 deeper insights into the physiological response of $E$. faecalis during phage infection, we employed

93 temporal transcriptomics of a VPE25 infection cycle. Transcriptomics revealed that VPE25

94 infection altered the expression of diverse genes involved in protein translation, metabolism,

95 bacterial community sensing, virulence and biofilm formation. Our work indicates that $E$. faecalis

96 reprograms transcription toward stress adaptation in response to phage infection. This suggests

97 that phages may impact the behavior of bacteria in polymicrobial communities including

98 bystanders that are not the intended targets of phage therapy.

99

100 Results

101 Transposon sequencing identifies novel genes involved in phage infection of $E$. faecalis.

102 To identify genetic determinants that confer phage resistance in $E$. faecalis, an $E$. 103 faecalis OG1RF transposon library consisting of 6,829 unique mutants was screened by 
sequence-defined mariner technology transposon sequencing (SMarT TnSeq) (33). $10^{7} \mathrm{CFU}$ of logarithmically growing $E$. faecalis TnSeq library pool was plated on solid media in the absence and presence of phage VPE25 at a multiplicity of infection (MOI) of 0.1 . Cells from the input library prior to plating and cells plated on plates containing no phage were used as controls. Tn insertions in E. faecalis genomic DNA were sequenced as described by Dale et al. (33). Sequencing reads were mapped to the $E$. faecalis OG1RF genome to identify bacterial mutants with altered phage sensitivity. The relative abundance of 22 E. faecalis mutants was enriched (adjusted $P$ value < $0.05, \log _{2}$ fold change $>0$ ) in the presence of VPE25 relative to cultures that lacked phage and the input library (Table S1, Fig. 1A). Five of the 22 phage-resistant enriched mutants harbored Tn insertions in OG1RF_10588 (Table S1, Fig. 1A), previously identified to encode the VPE25

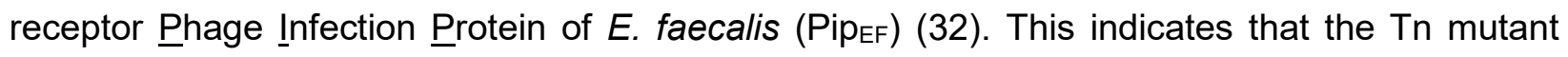
library is an appropriate tool for the discovery of genes involved in phage infection of $E$. faecalis. we analyzed several Tn mutants, including OG1RF_10820, OG1RF_10951 (cscK), OG1RF_12241, and OG1RF_12435, and three enterococcal polysaccharide antigen (Epa) associated genes, OG1RF_11715 (epaOX), OG1RF_11714, and OG1RF_11710 encoding two glycosyltransferases and an O-antigen ligase protein, respectively. (Table S1, Fig. 1A). polysaccharide (34). We and others have previously demonstrated that enterococcal phages unrelated to VPE25 utilize Epa to adsorb and infect E. faecalis (23, 35-37). Initial work from our

124 group showed that mutation of the VPE25 receptor PipeF prevented VPE25 DNA entry into E. 125 faecalis $\mathrm{V} 583$, yet phages could still adsorb to receptor mutants (32), suggesting that the factors 126 that promote phage infection via surface adsorption remained to be identified. Here, we show that 127 either in-frame deletion of OG1RF_11715 (epaOX) (38) or Tn insertions in epaOX, 128 OG1RF_11714, and OG1RF_11710 confer phage resistance to VPE25, similar to the pip $p_{E F}$ 129 receptor mutant (Fig. 1B). To assess the role of Epa during VPE25 infection, we investigated the 
ability of VPE25 to adsorb to wild type E. faecalis, the epaOX deletion mutant or the three epa Tn insertion mutants. Both wild type and the pip $p_{E F}$ mutant strain adsorbed significantly higher amounts of VPE25 as compared to the epa mutants (Fig. 1C). Together, these data indicate that epa-derived cell wall modifications contribute to VPE25 infection by promoting surface adsorption.

134 This is consistent with previous observations in other lactic acid bacteria that phage infection is a 135 two-step process: first phage must reversibly bind to a cell wall polysaccharide followed by the 136 committed initiation of DNA ejection into the cell (39-41).

137 In addition to epa genes, several Tn mutants whose roles during phage infection were 138 unknown were enriched on VPE25-containing agar compared to uninfected controls (Table S1, 139 Fig.1A). This included OG1RF_10820-Tn, cscK-Tn, and OG1RF_12241-Tn. OG1RF_10820 140 encodes a putative LytR response regulator. Homologs of this protein control multiple cellular 141 processes, including virulence, extracellular polysaccharide biosynthesis, quorum sensing, 142 competence and bacteriocin production (42). OG1RF_12241 is a homolog of the hypR (EF2958) 143 gene of $E$. faecalis strain $\mathrm{JH} 2-2$ and encodes a LysR family transcriptional regulator. HypR 144 regulates oxidative stress through the ahpCF (alkyl hydroperoxide reductase) operon conferring 145 increased survival in mouse peritoneal macrophages $(43,44)$. Lastly, CscK is a fructose kinase 146 that converts fructose to fructose-6-phosphate for entry into glycolysis (45). Considering that none 147 of these genes had previously been shown to be associated with phage infection, we asked how 148 Tn disruption of these genes influenced phage sensitivity using a time course phage infection 149 assay. In the presence of phage, the optical density of the Tn mutants OG1RF_10820-Tn, cscK150 Tn, and OG1RF_12241-Tn was maintained constant over time, whereas the growth of wild type 151 and the $p_{E F}$ receptor mutant declined or increased over the course of infection respectively (Fig. 152 2A). Complementation of the Tn mutants with wild type alleles restored phage susceptibility 153 without altering their growth in the absence of phage (Fig. S1A and S1B). To further investigate 154 this phage tolerance phenotype, we asked whether these mutants harbored a defect in phage 155 production. Assessment of the number of phage particles produced during infection showed that 
OG1RF_10820-Tn, cscK-Tn, and OG1RF_12241-Tn strains produced 10 - fold lower phage particles relative to the wild type strain (Fig. 2B), indicating that the Tn mutants have a defect in phage burst size. In the absence of phage, wild type, $\Delta p p_{E F}$, OG1RF_10820-Tn, cscK-Tn, and OG1RF_12241-Tn showed similar growth kinetics (Fig. 2C), suggesting that these mutations do not impair growth in laboratory media. These data indicate that deficiencies in transcriptional signaling and metabolism have a strong impact on lytic phage production in E. faecalis. reduced phage burst, releasing fewer viral particles relative to the wild type, we queried the status

164 of viral transcription and replication in these mutants. Whole genome transcriptomic analysis of 165 phage infected E. faecalis OG1RF cells indicated that the VPE25 genes orf76, orf111 and orf106 166 are highly expressed throughout the course of phage infection (Table S2A). However, the 167 transcripts of these genes were less abundant in the Tn mutants OG1RF_10820-Tn, cscK-Tn, and OG1RF_12241-Tn (Fig. S2A). Additionally, phage DNA replication is delayed in these Tn insertion mutants as judged by significantly lower copy number of phage DNA relative to the wild type strain (Fig. S2B). These data indicate that OG1RF_10820-Tn, cscK-Tn, and OG1RF_12241-

171 Tn mutants restrict VPE25 DNA replication which diminishes phage particle production.

Mutation of OG1RF_10820 alters epa variable gene expression negatively impacting phage

174 infection.

175 To further assess the roles of the OG1RF_10820, cscK, and OG1RF_12241 genes during 176 VPE25 infection, we performed phage adsorption assays with these strains. OG1RF_10820-Tn, 177 which harbors a Tn disrupted lytR response regulator gene, adsorbed $40 \%$ less phage compared 178 to the wild type control (Fig. 3A). Of the three Tn mutants, this was the only mutant that adsorbed 179 less phage compared to the wild type control. LytR type response regulators have been implicated 180 in the biosynthesis of extracellular polysaccharides, including alginate biosynthesis in 181 Pseudomonas aeruginosa $(42,46,47)$. Since phage adsorption of $E$. faecalis is facilitated by Epa, 
we measured epa gene expression in the OG1RF_10820-Tn background. The epa locus consists of core genes (epaA - epaR) that are conserved in E. faecalis, followed by a group of strain-

184 specific variable genes that reside downstream of the core genes $(37,48)$. The expression of epa variable genes epaOX, OG1RF_11714, and OG1RF_11710 were reduced in the absence of

186 OG1RF_10820 (lytR) during logarithmic and stationary phase growth (Fig. 3B). In contrast, 187 OG1RF_10820 disruption did not alter the expression of core epa genes (Fig. S3). Collectively, 188 these results indicate that mutation of the lytR homolog hinders optimum binding of VPE25 by 189 downregulating epa variable genes thereby modifying the polysaccharide decoration of the core 190 Epa structure (49).

\section{Hypermutator strains defective in mismatch repair facilitate acquisition of phage}

\section{resistance in E. faecalis.}

Transposon mutant OG1RF_12435-Tn, with an insertion in the DNA mismatch repair (MMR) gene mutS, was significantly overrepresented during VPE25 infection (Table S1, Fig. 1A). The MMR genes mutS and mutL correct replication associated mismatch DNA base errors (50). We discovered that VPE25-mediated lysis of the mutS-Tn-E (OG1RF_12435-Tn carrying the empty plasmid pAT28) and mutL-Tn-E (OG1RF_12434-Tn carrying the empty plasmid pAT28) mutants closely resembled wild-type lysis kinetics for $\sim 4$ hours post-infection and released similar numbers of phage particles (Fig. 4A and 4B). However, these mutator strains eventually started to recover and escape infection suggesting that the mutator phenotype gives rise to phage resistance (Fig. 4A). Introduction of the wild type mutS and mutL genes cloned into plasmid pAT28 (mutS-Tn-C and mutL-Tn-C) restored the wild type phage susceptibility phenotype (Fig. 4A). In the absence

204 of phage, the wild type, mutL-Tn and mutS-Tn strains grew similarly, suggesting that hypermutator 205 strains do not harbor growth defects in vitro (Fig. 4C).

206 To confirm that the mutS-Tn and mutL-Tn strains accumulate phage resistant isolates during 207 phage exposure, we performed phage infection assays using colonies of mutS-Tn and mutL-Tn 
grown overnight on agar plates in the absence and presence of VPE25. Consistent with our previous data, all mutS-Tn and mutL-Tn mutant colonies selected from agar plates lacking phage were initially phage sensitive, and over time became phage resistant (Fig. S4A and S4C). In

211 contrast, the mutL-Tn and mutS-Tn colonies acquired from the phage containing plates were

212 phage resistant and had similar growth kinetics to the pip $p_{E F}$ receptor mutant in the presence of

213 VPE25 (Fig. S4A and S4C). All isolates grew similarly in the absence of phage (Fig. S4B and

214 S4D). To gain insight into the basis of acquired phage resistance in the mismatch repair mutant

215 backgrounds we compared the phage adsorption profiles of the different strains. The mutL-Tn

216 and mutS-Tn mutants that were not pre-exposed to VPE25 adsorbed phage at $70-80 \%$

217 efficiency, whereas mutL-Tn and mutS-Tn colonies chosen from phage containing agar plates

218 displayed a severe phage adsorption defect (Fig. S4E and S4F). Our data show that phage

219 treatment leads to the selection and growth of phage-adsorption deficient isolates from mutL-Tn

220 and mutS-Tn mutator cultures, most likely through mutations in epa variable genes. This also

221 suggests that epa variable genes may be a hotspot for mutation in $E$. faecalis.

VPE25 infection drives global gene expression changes in E. faecalis.

To study temporal changes in E. faecalis gene expression during phage infection, we infected logarithmically growing E. faecalis with VPE25 at an MOI of 10 . The cell density of infected $E$. faecalis cultures was comparable to the uninfected control cultures during the first 10 min of 227 infection (Fig. 5A). Between 10 and 20 min post infection the VPE25 burst size increased as the 228 cell density of the infected culture declined (Fig. 5A and 5B). VPE25 particle numbers plateaued 22930 min post infection, and there was no significant increase in phage output between $30-50$ 230 minutes of infection (Fig. 5B).

231 To investigate the transcriptional response of $E$. faecalis during VPE25 infection we collected 232 cells at several time points during distinct phases of the VPE25 infection cycle and performed 233 RNA-Seq. Samples were collected at 10, 20, and 40 minutes post-infection representing the early, 
234 middle and late phase of the VPE25 infection cycle, respectively (Fig. 5A and 5B). Hierarchical 235 clustering of differentially expressed E. faecalis genes during VPE25 infection compared to 236 uninfected controls revealed unique gene expression patterns at each time point (Fig. 6A and 6B, 237 Table S2B). Gene expression patterns grouped into three distinct clusters that correlated with the 238 early, middle, and late stages of phage infection (Fig. 6A and 6B). Phages rely on host cell 239 resources for the generation of viral progeny. GO and KEGG enrichment analysis showed that 240 phage infection influenced numerous E. faecalis metabolic pathways, including amino acid, 241 carbohydrate, and nucleic acid metabolism (Table S2B).

242 Approximately $54 \%$ of the $E$. faecalis genome was differentially expressed $(P<0.05)$ relative 243 to uninfected controls, with 692 downregulated and 731 upregulated genes over the course of 244 phage infection (Fig. S5A and S5C). 37 of the 692 downregulated genes were repressed 245 throughout the course of phage infection and are broadly categorized as ribosome biogenesis 246 and bacterial translation genes (Fig.S5B, Table S3A), indicating that VPE25 modulates host 247 protein biogenesis to prevent bacterial growth and promote viral replication. In contrast, 248 expression of 110 genes belonging to DNA repair pathways, amino acyl-tRNA biosynthesis and 249 carbohydrate metabolism were significantly upregulated throughout the phage infection cycle 250 (Fig. 5D, Table S3B). The induction of DNA stress response genes suggests that $E$. faecalis cells 251 activate DNA defense mechanisms to counteract phage driven DNA damage.

252 Next, we assessed the transcriptome of VPE25 during infection. We detected 132 differentially 253 expressed VPE25 transcripts by comparing the average read counts of individual genes at 10, 20 254 and $40 \mathrm{~min}$ relative to the start of infection $(0 \mathrm{~min})$. Hierarchical clustering grouped differentially 255 expressed genes into early and late genes based on their distinct temporal expression patterns.

256 The transcripts of 78 early genes, including those predicted to be involved in nucleotide 257 biosynthesis and replication, accumulated during the first $10 \mathrm{~min}$ of infection (Fig. S6A, Table 258 S2A). In contrast, late genes encoding phage structural components, DNA packaging and host 259 cell lysis were induced by $40 \mathrm{~min}$ of infection (Fig. S6A, Table S2A). Approximately 90 genes 
260 (68\% of the VPE25 genome) annotated as hypothetical in the VPE25 genome were expressed 261 during the early or late phase of infection (Fig. S6A, Table S2A), indicating that the majority of 262 actively transcribed genes during VPE25 infection have no known function.

Phage infection modulates $E$. faecalis genes involved in group interactions.

Our transcriptomic data indicate that VPE25 infection causes a shift in the expression pattern of genes involved in pathways unrelated or peripheral to host metabolism and macromolecule biosynthesis (Fig. S5B and S5D). Most notably, we observed that phage infection led to a significant reduction in the expression of fsr quorum sensing genes and in the induction of type VII secretion system genes (T7SS) (Fig. S6B).

The E. faecalis fsr quorum sensing system is critical for virulence and biofilm formation in different animal models, including mouse models of endocarditis and peritonitis (51-55). The fsr quorum sensing system is comprised of the $f s r A, f s r B D$ and $f s r C$ genes (56-58). fsr $A$ encodes a

274 pheromone peptide and the membrane histidine kinase required for functional quorum sensing 275 regulated gene expression in E. faecalis. Quantitative real-time PCR (qPCR) confirmed that fsrBD 276 and $f s r C$ are repressed throughout VPE25 infection, with the strength of repression increasing 277 over time (Fig. 7A). There was negligible impact on fsrA mRNA levels (Fig. 7A) consistent with its 278 behavior as a constitutively expressed gene. qPCR analysis revealed several Fsr-controlled 279 genes to be differentially expressed during phage infection. Fsr-dependent virulence factors, 280 including gelE, sprE, OG1RF_10875 (EF1097), and OG1RF_10876 (EF1097b) genes (59) were 281 all significantly downregulated during phage infection relative to uninfected controls (Fig. 7A-B).

282 The fsr regulon is also an activator and repressor of several metabolic pathways (60). Our data 283 demonstrates that the levels of Fsr-activated genes involved in the phosphotransferase sugar 284 transport system (OG1RF_10296 and OG1RF_10297) are reduced, whereas negatively 285 regulated genes in the $f s r$ regulon, such as eutB, eutC and eutH genes involved in ethanolamine 
utilization are derepressed during VPE25 infection (Fig. 7B and 7C). These data suggest that VPE25 attenuates the FsrABDC system, consequently impacting $E$. faecalis virulence and metabolism.

Divergent forms of the T7SS (also known as the Ess/Esx system) are widely distributed in Gram-positive bacteria and the T7SS has been extensively studied in the Actinobacterium, Mycobacterium tuberculosis (61-66). To date, enterococcal T7SS loci remain uncharacterized. Consistent with our transcriptomic data (Fig. S6B), we observed that phage infection induces genes in the E. faecalis T7SS locus, including OG1RF_11100 (esxA), OG1RF_11101 (essA), OG1RF_11104 (essB), OG1RF_11105 (essC1), OG1RF_11109 and OG1RF_11115 (essC2) (Fig. 7D). The esXA and OG1RF_11109 genes encode potential WXG100 domain containing effector and LXG-domain toxin proteins, respectively. The secretion of T7SS factors is dependent on the EssB transmembrane protein, and FtsK/SpollIE ATPases encoded by the essC1 and essC2 genes. The T7SS in Gram-positive bacteria is involved in immune system activation, apoptosis of mammalian cells, bacterial cell development and lysis, DNA transfer and bacterial interspecies interactions $(62,67-77)$.

To investigate whether phage-mediated expression of $f s \mathrm{ABDC}$ and the T7SS genes are when infected with the unrelated phage NPV-1. mRNA levels of $f s r B$ and sprE were reduced whereas expression of the T7SS genes were elevated during NPV-1 infection (Fig. S6C), suggesting that phage specific control of quorum sensing and T7SS expression is not restricted 308 species infections.

\section{Discussion}



phages modulate bacterial physiology and will inform approaches toward effective phage

313 therapies against MDR bacteria. Commonly used approaches to identify phage resistant bacteria

314 often yield information restricted to phage receptors and/or adsorption mechanisms. While useful,

315 these approaches often overlook more subtle interactions that drive the efficiency of phage

316 infection and phage particle biogenesis. Additionally, these approaches provide minimal

317 information on how bacteria sense and respond to phage infection. These are important gaps in

318 knowledge considering the heightened interest in utilizing phages as clinical therapeutics against

319 difficult to treat bacterial infections. To begin to address these knowledge gaps we have studied

320 the model Gram-positive commensal and opportunistic pathogen $E$. faecalis when infected with

321 its cognate lytic phage VPE25. We have discovered several novel bacterial factors that are

322 indispensable for efficient VPE25 infection of E. faecalis. In addition, we have uncovered key

323 insights into the molecular events that are triggered in E. faecalis cells during phage infection.

324 Importantly, our work shows that E. faecalis alters the expression of genes associated with

325 environmental sensing and group interactions during phage infection. Such a response may have

326 unexpected consequences in polymicrobial communities, and our work sets the stage for studying

327 how phage therapies may impact non-target bacteria in the microbiota.

TnSeq identified numerous E. faecalis genes that govern VPE25 susceptibility. Mutations in epa variable genes conferred VPE25 resistance by preventing phage adsorption, similar to other E. faecalis phages $(23,35-37)$. We discovered that phage infection of mismatch repair gene

331 mutants results in the emergence of phage adsorption deficiencies, thus the mismatch repair 332 system likely fails to correct DNA damage of epa genes during phage infection. This suggests 333 that epa genes may be a hotspot for mutation. TnSeq also enabled the discovery of the LytR334 domain transcription factor encoded by OG1RF_10820 as a regulator of epa variable locus gene 335 expression (Fig. 3B). Considering an epa mutant strain of E. faecalis is defective in colonization 
and outgrowth during antibiotic selection in the intestine (23), we believe that future investigation of LytR mediated regulation of epa and potentially other genomic loci could guide the development of effective therapeutics to control $E$. faecalis colonization and infections.

This work has discovered bacterial metabolic and oxidative stress response genes that are

340 important for phage infection. Decreased phage replication coupled with lower burst size of

341 VPE25 in the fructose kinase mutant ( $\operatorname{cscK})$ suggests that VPE25 relies on host carbohydrate

342 metabolism to support viral progeny formation. The reliance of VPE25 on host CscK for viral

343 propagation is corroborated by RNA-Seq data showing broad induction of bacterial host

344 carbohydrate metabolism genes during VPE25 infection. Further, we observed that VPE25 lytic

345 growth leads to a gradual rise in the OG1RF_12241 transcripts which encode the LysR homolog

346 HypR, a regulator of oxidative stress. Phage infection enhanced the transcript levels of three other

347 oxidative stress response genes, including OG1RF_10348, OG1RF_10983, and OG1RF_11314

348 encoding superoxide dismutase ( $\operatorname{sod} A), \mathrm{NADH}$ peroxidase $(n p r)$ and catalase $(k a t A)$, respectively

349 (Table S2B). In Campylobacter jejuni, mutations in the LysR regulated gene ahpC, as well as sodB and kat $A$ resulted in reduced plaquing efficiency by the phage NCTC 12673 (27). We hypothesize that phage tolerance during hypersensitivity to oxidative stress could be detrimental to $E$. faecalis and targeting such pathways could be used to control E. faecalis colonization.

Our data indicate that putative T7SS genes are activated in response to phage infection. Although E. faecalis T7SS remains poorly characterized, the Staphylococcus aureus T7 system has been demonstrated to defend cells against neutrophil assault, enhance epithelial cell apoptosis and is critical for virulence $(68,69,78,79)$. Additionally, S. aureus T7SS maintains

357 membrane homeostasis and is involved in the membrane stress response $(69,80)$. The finding

358 that $E$. faecalis T7SS genes are induced in response to two different phages suggests phage 359 mediated membrane damage may lead to elevated T7SS gene expression. Finally, the S. aureus

360 T7SS nuclease toxin, EsaD, contributes to interspecies competition through growth inhibition of 361 rival strains lacking the EsaG anti-toxin (77). The impact of $S$. aureus T7SS on rival strains and 
the presence of T7SS genes in environmental isolates $(81,82)$ suggests a pivotal role of this secretion system in shaping microbial communities. Future studies on E. faecalis T7SS will aim to determine how this system influences intra- and/or interspecies competition and niche establishment in polymicrobial environments such as the microbiota.

In contrast to the T7SS, the bacterial population associated quorum sensing fsr locus was repressed during VPE25 infection in E. faecalis. Gram-negative bacteria can escape phage invasion by quorum sensing mediated downregulation of phage receptor expression or activation of CRISPR-Cas (clustered regularly interspaced short palindromic repeats) immunity (83-86). The fsr regulon does not include the receptor ( pip $_{E F}$ ), epa genes necessary for phage adsorption, or

371 CRISPR-Cas. However, the fsr system does contribute to biofilm formation that could potentially 372 deter phage infection $(55,87)$. VPE25 infection may attenuate fsr mediated biofilm formation to 373 favor continued infection of neighboring planktonic cells. On the other hand, phage genomes have 374 been shown to carry enzymes that degrade quorum sensing molecules or anti-CRISPR genes to 375 evade host defense strategies $(88,89)$. Although such anti-host accessory genes are not evident 376 in the VPE25 genome, it is possible that phage encoded hypothetical genes influence E. faecalis 377 quorum sensing and dictate molecular events that favor phage production. Identification of such 378 auxiliary phage proteins could lead to the discovery of potential anti-enterococcal therapeutics.

380 faecalis has revealed new insights into our understanding of phage-host interactions in 381 enterococci. Together, our results emphasize the importance of epa gene regulation, 382 carbohydrate metabolism and the oxidative stress response in successful phage predation. 383 Further, contributions of VPE25 on E. faecalis fsr and T7SS genes involved in inter- and intra384 bacterial interactions suggests that phage therapy could impact microbial community dynamics in 385 patients undergoing treatment, and such an outcome should be taken into consideration for the development of phage-based therapeutics. 


\section{Materials and methods}

Bacteria and bacteriophages. All bacteria and phages used in this study are listed in Table S4.

E. faecalis strains were grown with aeration on Todd-Hewitt broth (THB) or THB agar at $37^{\circ} \mathrm{C}$.

Escherichia coli was grown on Lennox L broth (LB) with aeration or on LB agar at $37^{\circ} \mathrm{C}$. The

following antibiotic concentrations were added to media for selection of $E$. coli or $E$. faecalis:

$25 \mu \mathrm{g} / \mathrm{ml}$ fusidic acid, $50 \mu \mathrm{g} / \mathrm{ml}$ rifampin, $750 \mu \mathrm{g} / \mathrm{ml}$ spectinomycin and $20 \mu \mathrm{g} / \mathrm{ml}$ chloramphenicol.

394 Phage sensitivity assays were performed on THB agar supplemented with $10 \mathrm{mM} \mathrm{MgSO}_{4}$.

Transposon library screen. $10^{8}$ colony forming units (CFU) of the E. faecalis OG1RF pooled transposon library was inoculated into $5 \mathrm{ml}$ of THB and grown with aeration to an optical density of $600 \mathrm{~nm}\left(\mathrm{OD}_{600}\right)$ of $0.5 \cdot 10^{7} \mathrm{CFU}$ of the library was spread onto a THB agar plate (10 replicates) containing $10 \mathrm{mM} \mathrm{MgSO}_{4}$ in the absence and presence of $10^{6}$ plaque forming units (PFU) of VPE25 $(\mathrm{MOI}=0.1)$. After overnight $(\mathrm{O} / \mathrm{N})$ incubation at $37^{\circ} \mathrm{C}$, bacterial growth from the control 401 and phage containing plates was resuspended in $5 \mathrm{ml}$ of phosphate buffered saline (PBS).

402 Genomic DNA was isolated from the input library and from three biological replicates of phage 403 exposed and unexposed samples using a ZymoBIOMICS TM DNA Miniprep Kit (Zymo Research), 404 following the manufacturers protocol.

Transposon library sequencing. Library preparation and sequencing was performed by the Microarray and Genomics Core at the University of Colorado Anschutz Medical Campus. A 408 detailed protocol is described by Dale et al. (33). Briefly, $100 \mathrm{ng}$ of genomic DNA was sheared to 409 approximately $400 \mathrm{bp}$ fragments and processed through the Illumina TruSeq Nano library 410 enrichment kit. 9 ng of each normalized library was used as PCR template to enrich for the mariner 411 transposon junctions using a transposon-specific primer (mariner-seq) and the Illumina P7 primer 412 (16 cycles of amplification). The enrichment PCR products were diluted 1:100, and $10 \mu \mathrm{l}$ was used 
413 as template for an indexing PCR of 9 cycles of amplification (TruSeq P5 indexing primer + P7

414 primer). The final libraries had unique combinations of P5 and P7 indexes suitable for multiplexed

415 sequencing. Sequencing was performed using Illumina NovaSeq 6000 in 150 base paired-end

416 format. Illumina adapter trimming, read mapping to the $E$. faecalis OG1RF reference sequence

417 (NC_017316.1) and statistical analysis of differentially abundant transposon mutants were

418 performed using previously published scripts found here

419 https://github.com/dunnylabumn/Ef OG1RF tnseq (33).

421 Bacterial spot assay on phage agar plates. $\mathrm{O} / \mathrm{N}$ bacterial cultures were pelleted and 422 resuspended in SM-plus buffer $(100 \mathrm{mM} \mathrm{NaCl}, 50 \mathrm{mM}$ Tris- $\mathrm{HCl}, 8 \mathrm{mM} \mathrm{MgSO}$, $5 \mathrm{mM} \mathrm{CaCl} 2 \mathrm{LpH}$

$4237.4]$ ) and normalized to an $\mathrm{OD}_{600}$ of 1.0 .10 -fold serial dilutions of the bacterial cultures were 424 spotted onto THB agar plates with or without $5 \times 10^{6} \mathrm{PFU} / \mathrm{ml}$ of VPE25. The plates were incubated 425 at $37^{\circ} \mathrm{C} \mathrm{O} / \mathrm{N}$.

427 Phage sensitivity and burst kinetic assays. O/N cultures of $E$. faecalis were subcultured to a 428 starting $\mathrm{OD}_{600}$ of $0.025 \mathrm{in} 25 \mathrm{ml}$ of THB. When the bacterial culture reached mid-logarithmic phase $429\left(\mathrm{OD}_{600} \sim 0.5\right), 10 \mathrm{mM} \mathrm{MgSO}_{4}$ and VPE25 (MOI of 0.1 or 10$)$ were added. $\mathrm{OD}_{600}$ was monitored for $430 \sim 7 \mathrm{hrs}$. To investigate if phage progeny were produced and released from the bacterial cells upon 431 VPE25 infection, $250 \mu$ l of culture was collected at different time points over the course of infection 432 and thoroughly mixed with $1 / 3$ volume of chloroform. The aqueous phase containing phages was 433 separated from the chloroform by centrifugation at $24,000 \times g$ for $1 \mathrm{~min}$ and the phage titer was 434 determined using a THB agar overlay plaque assay. Data are presented as the average of three 435 replicates with +/- standard deviation.

437 Bacterial growth curves. $25 \mathrm{ml}$ of THB was inoculated with $\mathrm{O} / \mathrm{N}$ cultures of $E$. faecalis to obtain 438 a starting $\mathrm{OD}_{600}$ of 0.025 . Cultures were incubated at $37^{\circ} \mathrm{C}$ with aeration. $\mathrm{OD}_{600}$ was measured 
periodically for $\sim 7$ hours. Growth curves are presented as the average of three biological

440 replicates.

442 Phage adsorption assay. A bacterial culture grown $\mathrm{O} / \mathrm{N}$ was pelleted at $3,220 \times \mathrm{g}$ for $10 \mathrm{~min}$ and

443 resuspended to $10^{8} \mathrm{CFU} / \mathrm{ml}$ in SM-plus buffer. The cell suspensions were mixed with phages at

444 an $\mathrm{MOI}$ of 0.1 and incubated at room temperature without agitation for $10 \mathrm{~min}$. The bacterium-

445 phage suspensions were centrifuged at $24,000 \times g$ for $1 \mathrm{~min}$, and the supernatant was collected

446 and phages were enumerated by a plaque assay. SM-plus buffer with phage only (no bacteria)

447 served as a control. Percent adsorption was determined as follows: $\left[\left(\mathrm{PFU}_{\text {control }}-\mathrm{PFU}_{\text {test }}\right.\right.$

448 supernatant $/ \mathrm{PFU}_{\text {control] }} \times 100$. Data are presented as the average of three replicates $+/$ - standard

449 deviation.

Complementation of Tn mutants. All PCR reactions used for cloning were performed with high

452 fidelity KOD Hot Start DNA Polymerase (EMD Millipore). Approximately 100 bp of upstream

453 flanking DNA and the coding regions of OG1RF_10820, OG1RF_10951 (cscK), OG1RF_12241,

454 OG1RF_12435 (mutS) and OG1RF_12434 (mutL) were cloned into the shuttle vector pAT28 (90).

455 The primer sequences and restriction enzymes used for cloning are listed in Table S4. Plasmids

456 were introduced into electrocompetent $E$. faecalis cells as previously described (23).

458 RNA extraction and quantitative PCR. RNA was extracted from uninfected or VPE25 infected

459 E. faecalis by using an RNeasy Mini Kit (Qiagen) with the following modifications. Cell pellets 460 were incubated in $100 \mu \mathrm{L}$ of $15 \mathrm{mg} / \mathrm{ml}$ lysozyme (Amersco) for $30 \mathrm{~min}$ at room temperature. 700 $461 \mu$ of RLT buffer containing $\beta$-mercaptoethanol (manufacturers recommended concentration) was 462 added and the samples were bead beat in Lysing Matix B tubes (MP Bio) at 45 sec intervals for 463 a total time of $4.5 \mathrm{~min}$. Debris was centrifuged at $24,000 \times g$ for $1 \mathrm{~min}$ and the supernatant was 464 transferred to a fresh tube. $590 \mu \mathrm{L}$ of $80 \%$ ethanol per $760 \mu \mathrm{L}$ supernatant was added and the 
entire volume was loaded onto an RNeasy column following the standard Qiagen RNA purification protocol. cDNA was synthesized from $1 \mu \mathrm{g}$ of total RNA using qScript cDNA SuperMix

467 (QuantaBio) $\left(25^{\circ} \mathrm{C}\right.$ for 5 minutes, $42^{\circ} \mathrm{C}$ for 30 minutes and $85^{\circ} \mathrm{C}$ for 5 minutes). Transcript levels

468 were analyzed by qPCR using PowerUp ${ }^{\text {TM }}$ SYBR Green Master Mix (Applied Biosystems) and 469 transcript abundances were normalized to the 16S rRNA transcripts. VPE25 orf_76 copy number 470 was determined by qPCR using orf_76 cloned into pCR4-TOPO ${ }^{\text {TM }}$ TA cloning vector (Invitrogen)

471 as a standard. All data are represented as the average of three replicates $+/$ - the standard 472 deviation.

474 RNA sequencing and bioinformatics analysis. O/N cultures of $E$. faecalis were subcultured to 475 a starting $\mathrm{OD}_{600}$ of 0.025 in $50 \mathrm{ml}$ of $\mathrm{THB}$. When the bacterial culture reached mid-logarithmic 476 phase $\left(\mathrm{OD}_{600} \sim 0.5\right), 10 \mathrm{mM} \mathrm{MgSO}_{4}$ and VPE25 (MOI of 10$)$ were added. $4 \mathrm{ml}$ of cell suspension 477 was pelleted from the uninfected and infected cultures after $0,10,20$ and 40 minutes post VPE25 478 treatment. The pellets were washed with $4 \mathrm{ml}$ of PBS three times, followed by a wash with $2 \mathrm{ml}$ 479 RNAlater ${ }^{\mathrm{TM}}$ (Invitrogen) and RNA isolation was performed as described above. RNASeq libraries 480 were constructed using the Ribo Depleted library construction kit for Gram-positive Bacteria 481 (Illumina). Sequencing was performed using Illumina NovaSeq 6000 in 150 base paired-end 482 format. RNASeq data were analyzed using Geneious R11. Sequencing reads were mapped to 483 the E. faecalis OG1RF (NC_017316.1) and VPE25 (LT546030.1) genomes using Bowtie2. Gene 484 expression values were calculated by reads per kilobase per million which normalizes the raw 485 count by transcript length and sequence depth. Differential expression between two samples was 486 determined using the default Geneious R11 method with median ratios across all the transcripts 487 as the normalization scale. Genes with a fold change of $\geq 2.0$ and $P$ values $\leq 0.05$ were considered 488 significantly differentially expressed. Blast2GO basic tool was used to assign gene ontology (GO) 489 terms to $E$. faecalis OG1RF genes (91). KEGG pathway analysis was performed using the KEGG 
annotation server (92). The ClueGo plug-in for Cytoscape 3.6.1 $(93,94)$ was used to visualize gene clustering based on GO terms and KEGG annotations.

Statistical analysis. Statistical tests were performed using GraphPad - Prism version 8.2.1. For

494 bacterial growth assays in the presence and absence of phage, mutant $E$. faecalis was compared

495 to the wild type using two-way analysis of variance (ANOVA). For qPCR and phage adsorption

496 assays, unpaired Student's t-tests were used. $P$ values are indicated in the figure legends.

Data availability. The RNA-Seq reads associated with this study have been deposited at the ArrayExpress database at EMBL-EBI under accession number E-MTAB-8546. Tn-Seq reads have been deposited at the European Nucleotide Archive under accession number PRJEB35492.

Acknowledgments

This work was supported by National Institutes of Health grants R01Al141479 (B.A.D.) and

504 R01Al116610 (K.L.P.). J.L.E.W. was supported by American Heart Association Grant 19POST34450124 / Julia Willett / 2018. We would like to thank Katrina Diener and Monica

507 Core for the development of a customized Tn-Seq library preparation protocol.

\section{References}

511 1. Lebreton F, Willems RJL, Gilmore MS. 2014. Enterococcus diversity, origins in nature, and gut colonization. In Gilmore MS, Clewell DB, Ike Y, Shankar N (ed), Enterococci: From Commensals to Leading Causes of Drug Resistant Infection, Boston. 
514 2. Hidron Al, Edwards JR, Patel J, Horan TC, Sievert DM, Pollock DA, Fridkin SK, National Healthcare Safety Network T, Participating National Healthcare Safety Network F. 2008. NHSN annual update: antimicrobial-resistant pathogens associated with healthcareassociated infections: annual summary of data reported to the National Healthcare Safety Network at the Centers for Disease Control and Prevention, 2006-2007. Infect Control

3. Onderdonk AB, Bartlett JG, Louie T, Sullivan-Seigler N, Gorbach SL. 1976. Microbial Hosp Epidemiol 29:996-1011.

4. Al-Nassir WN, Sethi AK, Li Y, Pultz MJ, Riggs MM, Donskey CJ. 2008. Both oral metronidazole and oral vancomycin promote persistent overgrowth of vancomycinresistant enterococci during treatment of Clostridium difficile-associated disease. Antimicrob Agents Chemother 52:2403-6.

5. Ubeda C, Taur Y, Jenq RR, Equinda MJ, Son T, Samstein M, Viale A, Socci ND, van den Brink MR, Kamboj M, Pamer EG. 2010. Vancomycin-resistant Enterococcus domination of intestinal microbiota is enabled by antibiotic treatment in mice and precedes

6. Zirakzadeh A, Patel R. 2006. Vancomycin-resistant enterococci: colonization, infection, detection, and treatment. Mayo Clin Proc 81:529-36.

532 7. Arias CA, Panesso D, McGrath DM, Qin X, Mojica MF, Miller C, Diaz L, Tran TT, Rincon S, Barbu EM, Reyes J, Roh JH, Lobos E, Sodergren E, Pasqualini R, Arap W, Quinn JP, Shamoo Y, Murray BE, Weinstock GM. 2011. Genetic basis for in vivo daptomycin resistance in enterococci. N Engl J Med 365:892-900. 
536 8. Liu Y, Wang Y, Wu C, Shen Z, Schwarz S, Du XD, Dai L, Zhang W, Zhang Q, Shen J. 2012. First report of the multidrug resistance gene cfr in Enterococcus faecalis of animal

9. Munoz-Price LS, Lolans K, Quinn JP. 2005. Emergence of resistance to daptomycin origin. Antimicrob Agents Chemother 56:1650-4.

10. Patel SN, Memari N, Shahinas D, Toye B, Jamieson FB, Farrell DJ. 2013. Linezolid resistance in Enterococcus faecium isolated in Ontario, Canada. Diagn Microbiol Infect

11. Palmer KL, Kos VN, Gilmore MS. 2010. Horizontal gene transfer and the genomics of enterococcal antibiotic resistance. Curr Opin Microbiol 13:632-9.

547 12. Kurenbach B, Bohn C, Prabhu J, Abudukerim M, Szewzyk U, Grohmann E. 2003. Intergeneric transfer of the Enterococcus faecalis plasmid pIP501 to Escherichia coli and

13. Chang S, Sievert DM, Hageman JC, Boulton ML, Tenover FC, Downes FP, Shah S, Rudrik Streptomyces lividans and sequence analysis of its tra region. Plasmid 50:86-93.

554 14. Vicente MF, Baquero F, Perez-Diaz JC. 1988. Conjugative acquisition and expression of antibiotic resistance determinants in Listeria spp. J Antimicrob Chemother 21:309-18. 
15. Pucci MJ, Monteschio ME, Kemker CL. 1988. Intergeneric and intrageneric conjugal transfer of plasmid-encoded antibiotic resistance determinants in Leuconostoc spp. Appl

16. Jasni AS, Mullany P, Hussain H, Roberts AP. 2010. Demonstration of conjugative Environ Microbiol 54:281-7.

17. Weigel LM, Clewell DB, Gill SR, Clark NC, McDougal LK, Flannagan SE, Kolonay JF, Shetty J, Killgore GE, Tenover FC. 2003. Genetic analysis of a high-level vancomycinresistant isolate of Staphylococcus aureus. Science 302:1569-71.

18. Khalifa L, Brosh Y, Gelman D, Coppenhagen-Glazer S, Beyth S, Poradosu-Cohen R, Que YA, Beyth N, Hazan R. 2015. Targeting Enterococcus faecalis biofilms with phage therapy. Appl Environ Microbiol 81:2696-705.

19. Biswas B, Adhya S, Washart P, Paul B, Trostel AN, Powell B, Carlton R, Merril CR. 2002. Bacteriophage therapy rescues mice bacteremic from a clinical isolate of vancomycinresistant Enterococcus faecium. Infect Immun 70:204-10.

20. Zhang W, Mi Z, Yin X, Fan H, An X, Zhang Z, Chen J, Tong Y. 2013. Characterization of Enterococcus faecalis phage IME-EF1 and its endolysin. PLoS One 8:e80435.

573 21. Melo LDR, Ferreira R, Costa AR, Oliveira H, Azeredo J. 2019. Efficacy and safety assessment of two enterococci phages in an in vitro biofilm wound model. Sci Rep 9:6643.

575 22. Al-Zubidi M, Widziolek M, Court EK, Gains AF, Smith RE, Ansbro K, Alrafaie A, Evans C, Murdoch C, Mesnage S, Douglas CWI, Rawlinson A, Stafford GP. 2019. Identification of 
novel bacteriophages with therapeutic potential that target Enterococcus faecalis. Infect Immun 87.

23. Chatterjee A, Johnson CN, Luong P, Hullahalli K, McBride SW, Schubert AM, Palmer KL, Carlson PE, Jr., Duerkop BA. 2019. Bacteriophage resistance alters antibiotic-mediated intestinal expansion of enterococci. Infect Immun 87.

24. Drulis-Kawa Z, Majkowska-Skrobek G, Maciejewska B. 2015. Bacteriophages and phagederived proteins-application approaches. Curr Med Chem 22:1757-73. planktonic piracy: how phages command the microbial high seas. Virol J 16:15.

26. Yang Z, Yin S, Li G, Wang J, Huang G, Jiang B, You B, Gong Y, Zhang C, Luo X, Peng Y, Zhao X. 2019. Global transcriptomic analysis of the interactions between phage phiAbp1 and extensively drug-resistant Acinetobacter baumannii. mSystems 4.

27. Sacher JC, Flint A, Butcher J, Blasdel B, Reynolds HM, Lavigne R, Stintzi A, Szymanski CM. 2018. Transcriptomic analysis of the Campylobacter jejuni response to T4-like phage NCTC 12673 infection. Viruses 10.

28. Mojardin L, Salas M. 2016. Global transcriptional analysis of virus-host interactions between phage Фphi29 and Bacillus subtilis. J Virol 90:9293-304.

29. Leskinen K, Blasdel BG, Lavigne R, Skurnik M. 2016. RNA-sequencing reveals the progression of phage-host interactions between phiR1-37 and Yersinia enterocolitica. Viruses 8:111. 
approaches reveal a massive alteration of host RNA metabolism during bacteriophage infection of Pseudomonas aeruginosa. PLoS Genet 12:e1006134.

31. Jorth P, Trivedi U, Rumbaugh K, Whiteley M. 2013. Probing bacterial metabolism during infection using high-resolution transcriptomics. J Bacteriol 195:4991-8.

32. Duerkop BA, Huo W, Bhardwaj P, Palmer KL, Hooper LV. 2016. Molecular basis for lytic bacteriophage resistance in enterococci. MBio 7.

33. Dale JL, Beckman KB, Willett JLE, Nilson JL, Palani NP, Baller JA, Hauge A, Gohl DM, analysis of the Enterococcus faecalis core genome using an ordered, sequence-defined collection of insertional mutations in strain OG1RF. mSystems 3.

34. Xu Y, Murray BE, Weinstock GM. 1998. A cluster of genes involved in polysaccharide biosynthesis from Enterococcus faecalis OG1RF. Infect Immun 66:4313-23.

35. Ho K, Huo W, Pas S, Dao R, Palmer KL. 2018. Loss-of-function mutations in epaR confer resistance to $\phi N P V 1$ infection in Enterococcus faecalis OG1RF. Antimicrob Agents Chemother 62.

36. Lossouarn J, Briet A, Moncaut E, Furlan S, Bouteau A, Son O, Leroy M, DuBow MS, Lecointe F, Serror P, Petit MA. 2019. Enterococcus faecalis countermeasures defeat a virulent Picovirinae bacteriophage. Viruses 11.

617 37. Teng F, Singh KV, Bourgogne A, Zeng J, Murray BE. 2009. Further characterization of the epa gene cluster and Epa polysaccharides of Enterococcus faecalis. Infect Immun 77:3759-67. 
620 38. Dale JL, Cagnazzo J, Phan CQ, Barnes AM, Dunny GM. 2015. Multiple roles for 621 Enterococcus faecalis glycosyltransferases in biofilm-associated antibiotic resistance, cell envelope integrity, and conjugative transfer. Antimicrob Agents Chemother 59:4094-105.

623 39. Baptista C, Santos MA, Sao-Jose C. 2008. Phage SPP1 reversible adsorption to Bacillus subtilis cell wall teichoic acids accelerates virus recognition of membrane receptor YueB.

40. Monteville MR, Ardestani B, Geller BL. 1994. Lactococcal bacteriophages require a host J Bacteriol 190:4989-96.

41. Sao-Jose C, Baptista C, Santos MA. 2004. Bacillus subtilis operon encoding a membrane receptor for bacteriophage SPP1. J Bacteriol 186:8337-46.

42. Nikolskaya AN, Galperin MY. 2002. A novel type of conserved DNA-binding domain in the transcriptional regulators of the AlgR/AgrA/LytR family. Nucleic Acids Res 30:2453-9.

43. Verneuil N, Sanguinetti M, Le Breton Y, Posteraro B, Fadda G, Auffray Y, Hartke A, Giard JC. 2004. Effects of the Enterococcus faecalis hypR gene encoding a new transcriptional

637 44. La Carbona S, Sauvageot N, Giard JC, Benachour A, Posteraro B, Auffray Y, Sanguinetti 638 M, Hartke A. 2007. Comparative study of the physiological roles of three peroxidases (NADH peroxidase, alkyl hydroperoxide reductase and thiol peroxidase) in oxidative stress response, survival inside macrophages and virulence of Enterococcus faecalis. Mol Microbiol 66:1148-63. 
642 45. Sabri S, Nielsen LK, Vickers CE. 2013. Molecular control of sucrose utilization in Escherichia coli W, an efficient sucrose-utilizing strain. Appl Environ Microbiol 79:478-87.

644 46. Mohr CD, Leveau JH, Krieg DP, Hibler NS, Deretic V. 1992. AlgR-binding sites within the alg $D$ promoter make up a set of inverted repeats separated by a large intervening segment

47. Mohr CD, Hibler NS, Deretic V. 1991. AlgR, a response regulator controlling mucoidy in of DNA. J Bacteriol 174:6624-33.

48. Palmer KL, Godfrey P, Griggs A, Kos VN, Zucker J, Desjardins C, Cerqueira G, Gevers Comparative genomics of enterococci: variation in Enterococcus faecalis, clade structure in E. faecium, and defining characteristics of E. gallinarum and E. casseliflavus. MBio

49. Smith RE, Salamaga B, Szkuta P, Hajdamowicz N, Prajsnar TK, Bulmer GS, Fontaine T, Kolodziejczyk J, Herry JM, Hounslow AM, Williamson MP, Serror P, Mesnage S. 2019. 3:e00318-11. Decoration of the enterococcal polysaccharide antigen EPA is essential for virulence, cell surface charge and interaction with effectors of the innate immune system. PLoS Pathog 15:e1007730.

661 51. Singh KV, Nallapareddy SR, Nannini EC, Murray BE. 2005. Fsr-independent production of protease(s) may explain the lack of attenuation of an Enterococcus faecalis fsr mutant versus a gelE-sprE mutant in induction of endocarditis. Infect Immun 73:4888-94. 
664 52. Qin X, Singh KV, Weinstock GM, Murray BE. 2000. Effects of Enterococcus faecalis fsr genes on production of gelatinase and a serine protease and virulence. Infect Immun

53. Mohamed JA, Huang W, Nallapareddy SR, Teng F, Murray BE. 2004. Influence of origin 68:2579-86.

54. Hufnagel M, Koch S, Creti R, Baldassarri L, Huebner J. 2004. A putative sugar-binding transcriptional regulator in a novel gene locus in Enterococcus faecalis contributes to production of biofilm and prolonged bacteremia in mice. J Infect Dis 189:420-30.

673 55. Hancock LE, Perego M. 2004. The Enterococcus faecalis fsr two-component system controls biofilm development through production of gelatinase. J Bacteriol 186:5629-39.

675 56. Nakayama J, Chen S, Oyama N, Nishiguchi K, Azab EA, Tanaka E, Kariyama R, 676 Sonomoto K. 2006. Revised model for Enterococcus faecalis fsr quorum-sensing system: the small open reading frame $f s r D$ encodes the gelatinase biosynthesis-activating

679 57. Qin X, Singh KV, Weinstock GM, Murray BE. 2001. Characterization of fsr, a regulator controlling expression of gelatinase and serine protease in Enterococcus faecalis OG1RF.

58. Nakayama J, Cao Y, Horii T, Sakuda S, Akkermans AD, de Vos WM, Nagasawa H. 2001. sensing in Enterococcus faecalis. Mol Microbiol 41:145-54. 
59. Del Papa MF, Perego M. 2011. Enterococcus faecalis virulence regulator FsrA binding to target promoters. J Bacteriol 193:1527-32.

60. Bourgogne A, Hilsenbeck SG, Dunny GM, Murray BE. 2006. Comparison of OG1RF and an isogenic $f s r B$ deletion mutant by transcriptional analysis: the Fsr system of Enterococcus faecalis is more than the activator of gelatinase and serine protease. $\mathrm{J}$

61. Abdallah AM, Gey van Pittius NC, Champion PA, Cox J, Luirink J, Vandenbroucke-Grauls Bacteriol 188:2875-84.

62. Stanley SA, Raghavan S, Hwang WW, Cox JS. 2003. Acute infection and macrophage subversion by Mycobacterium tuberculosis require a specialized secretion system. Proc Natl Acad Sci U S A 100:13001-6.

63. Pym AS, Brodin P, Majlessi L, Brosch R, Demangel C, Williams A, Griffiths KE, Marchal G, Leclerc C, Cole ST. 2003. Recombinant BCG exporting ESAT-6 confers enhanced protection against tuberculosis. Nat Med 9:533-9.

64. Lewis KN, Liao R, Guinn KM, Hickey MJ, Smith S, Behr MA, Sherman DR. 2003. Deletion of RD1 from Mycobacterium tuberculosis mimics bacille Calmette-Guerin attenuation. J Infect Dis 187:117-23.

65. Pallen MJ. 2002. The ESAT-6/WXG100 superfamily - and a new Gram-positive secretion system? Trends Microbiol 10:209-12. 
705

706

707

708

709

710

711

712

713

714

715

716

71. Burts ML, DeDent AC, Missiakas DM. 2008. EsaC substrate for the ESAT-6 secretion

66. Gey Van Pittius NC, Gamieldien J, Hide W, Brown GD, Siezen RJ, Beyers AD. 2001. The ESAT-6 gene cluster of Mycobacterium tuberculosis and other high G+C Gram-positive bacteria. Genome Biol 2:RESEARCH0044.

67. Whitney JC, Peterson SB, Kim J, Pazos M, Verster AJ, Radey MC, Kulasekara HD, Ching MQ, Bullen NP, Bryant D, Goo YA, Surette MG, Borenstein E, Vollmer W, Mougous JD. 2017. A broadly distributed toxin family mediates contact-dependent antagonism between gram-positive bacteria. Elife 6.

68. Korea CG, Balsamo G, Pezzicoli A, Merakou C, Tavarini S, Bagnoli F, Serruto D, Unnikrishnan M. 2014. Staphylococcal Esx proteins modulate apoptosis and release of intracellular Staphylococcus aureus during infection in epithelial cells. Infect Immun 82:4144-53.

69. Kneuper H, Cao ZP, Twomey KB, Zoltner M, Jager F, Cargill JS, Chalmers J, van der Kooi-Pol MM, van Dijl JM, Ryan RP, Hunter WN, Palmer T. 2014. Heterogeneity in ess transcriptional organization and variable contribution of the Ess/Type VII protein secretion system to virulence across closely related Staphylocccus aureus strains. Mol Microbiol 93:928-43.

70. Aguilo Jl, Alonso H, Uranga S, Marinova D, Arbues A, de Martino A, Anel A, Monzon M, Badiola J, Pardo J, Brosch R, Martin C. 2013. ESX-1-induced apoptosis is involved in cellto-cell spread of Mycobacterium tuberculosis. Cell Microbiol 15:1994-2005.

pathway and its role in persistent infections of Staphylococcus aureus. Mol Microbiol 69:736-46. 
727 72. Stanley SA, Johndrow JE, Manzanillo P, Cox JS. 2007. The Type I IFN response to infection with Mycobacterium tuberculosis requires ESX-1-mediated secretion and contributes to pathogenesis. J Immunol 178:3143-52.

73. Brodin P, Majlessi L, Marsollier L, de Jonge MI, Bottai D, Demangel C, Hinds J, Neyrolles O, Butcher PD, Leclerc C, Cole ST, Brosch R. 2006. Dissection of ESAT-6 system 1 of Mycobacterium tuberculosis and impact on immunogenicity and virulence. Infect Immun

74. Guinn KM, Hickey MJ, Mathur SK, Zakel KL, Grotzke JE, Lewinsohn DM, Smith S, 74:88-98. Sherman DR. 2004. Individual RD1-region genes are required for export of ESAT-6/CFP10 and for virulence of Mycobacterium tuberculosis. Mol Microbiol 51:359-70.

737 75. Flint JL, Kowalski JC, Karnati PK, Derbyshire KM. 2004. The RD1 virulence locus of Mycobacterium tuberculosis regulates DNA transfer in Mycobacterium smegmatis. Proc Natl Acad Sci U S A 101:12598-603.

76. Hsu T, Hingley-Wilson SM, Chen B, Chen M, Dai AZ, Morin PM, Marks CB, Padiyar J, Goulding C, Gingery M, Eisenberg D, Russell RG, Derrick SC, Collins FM, Morris SL, King $\mathrm{CH}$, Jacobs WR, Jr. 2003. The primary mechanism of attenuation of bacillus CalmetteGuerin is a loss of secreted lytic function required for invasion of lung interstitial tissue. Proc Natl Acad Sci U S A 100:12420-5.

745 77. Cao Z, Casabona MG, Kneuper H, Chalmers JD, Palmer T. 2016. The type VII secretion system of Staphylococcus aureus secretes a nuclease toxin that targets competitor bacteria. Nat Microbiol 2:16183. 
78. Wang Y, Hu M, Liu Q, Qin J, Dai Y, He L, Li T, Zheng B, Zhou F, Yu K, Fang J, Liu X, Otto M, Li M. 2016. Role of the ESAT-6 secretion system in virulence of the emerging

79. Burts ML, Williams WA, DeBord K, Missiakas DM. 2005. EsxA and EsxB are secreted by community-associated Staphylococcus aureus lineage ST398. Sci Rep 6:25163. an ESAT-6-like system that is required for the pathogenesis of Staphylococcus aureus infections. Proc Natl Acad Sci U S A 102:1169-74.

80. Casabona MG, Buchanan G, Zoltner M, Harkins CP, Holden MTG, Palmer T. 2017. Functional analysis of the EsaB component of the Staphylococcus aureus Type VII secretion system. Microbiology 163:1851-1863.

81. Baptista C, Barreto HC, Sao-Jose C. 2013. High levels of DegU-P activate an Esat-6-like secretion system in Bacillus subtilis. PLoS One 8:e67840.

82. Akpe San Roman S, Facey PD, Fernandez-Martinez L, Rodriguez C, Vallin C, Del Sol R, Dyson P. 2010. A heterodimer of EsxA and EsxB is involved in sporulation and is secreted by a type VII secretion system in Streptomyces coelicolor. Microbiology 156:1719-29.

83. Hoyland-Kroghsbo NM, Paczkowski J, Mukherjee S, Broniewski J, Westra E, BondyDenomy J, Bassler BL. 2017. Quorum sensing controls the Pseudomonas aeruginosa CRISPR-Cas adaptive immune system. Proc Natl Acad Sci U S A 114:131-135.

84. Patterson AG, Jackson SA, Taylor C, Evans GB, Salmond GPC, Przybilski R, Staals RHJ, Fineran PC. 2016. Quorum sensing controls adaptive immunity through the regulation of multiple CRISPR-Cas systems. Mol Cell 64:1102-1108. 
770 86. Hoyland-Kroghsbo NM, Maerkedahl RB, Svenningsen SL. 2013. A quorum-sensing$771 \quad$ induced bacteriophage defense mechanism. MBio 4:e00362-12.

772 87. Abedon ST. 2017. Phage "delay" towards enhancing bacterial escape from biofilms: a 773 more comprehensive way of viewing resistance to bacteriophages. AIMS Microbiol 3:186226.

775

88. Hargreaves KR, Kropinski AM, Clokie MR. 2014. Bacteriophage behavioral ecology: How phages alter their bacterial host's habits. Bacteriophage 4:e29866.

89. Bondy-Denomy J, Pawluk A, Maxwell KL, Davidson AR. 2013. Bacteriophage genes that inactivate the CRISPR/Cas bacterial immune system. Nature 493:429-32.

90. Trieu-Cuot P, Carlier C, Poyart-Salmeron C, Courvalin P. 1990. A pair of mobilizable shuttle vectors conferring resistance to spectinomycin for molecular cloning in Escherichia coli and in Gram-positive bacteria. Nucleic Acids Res 18:4296.

91. Gotz S, Garcia-Gomez JM, Terol J, Williams TD, Nagaraj SH, Nueda MJ, Robles M, Talon M, Dopazo J, Conesa A. 2008. High-throughput functional annotation and data mining with the Blast2GO suite. Nucleic Acids Res 36:3420-35.

92. Moriya Y, Itoh M, Okuda S, Yoshizawa AC, Kanehisa M. 2007. KAAS: an automatic genome annotation and pathway reconstruction server. Nucleic Acids Res 35:W182-5.

93. Shannon P, Markiel A, Ozier O, Baliga NS, Wang JT, Ramage D, Amin N, Schwikowski B, Ideker T. 2003. Cytoscape: a software environment for integrated models of biomolecular interaction networks. Genome Res 13:2498-504. 
Figure legends

Figure 1. Transposon mutant library screening reveals $E$. faecalis genes important for abundance of select mutants from an E. faecalis OG1RF Tn library pool compared phage VPE25 naïve $E$. faecalis controls (false discovery rate $=0.05$ ). Phage resistant/tolerant mutants of interest

804 Phage VPE25 resistance phenotypes of an isogenic epa deletion strain or epa-specific Tn mutants serially diluted onto THB agar plates with or without $5 \times 10^{6} \mathrm{PFU} / \mathrm{ml}$ of VPE25. (C) VPE25 efficiently adsorbs to wild type $E$. faecalis OG1RF wild type and an isogenic $\Delta p i p_{E F}$ deletion strain

807 but not to the various epa mutants.

809 Figure 2. VPE25 mediated killing is halted and phage production is reduced during 810 infection of OG1RF_10820-Tn, cscK-Tn and OG1RF_12241-Tn transposon mutants. (A)

811 VPE25 killing curves and (B) VPE25 particle production kinetics using the indicated E. faecalis

812 transposon mutant strains compared to the wild type or $\Delta p i p_{E F}$ deletion strains. The inset 813 highlights the delayed lysis phenotype of the transposon mutants relative to wild type. (C) Growth

814 curves of all the strains in the absence of VPE25. Data show three independent experiments 815 combined and presented as the mean with standard deviation. ${ }^{*} P<0.0001$ by two-way analysis 816 of variance (ANOVA). 
818 Figure 3. Mutation of a lytR homolog downregulates the expression of epa variable genes

819 leading to decreased VPE25 adsorption. (A) Phage adsorption assay showing that the

820 OG1RF_10820-Tn mutant strain is defective for VPE25 attachment relative to the wild type strain.

821 Disruption of OG1RF_10820 (lytR) leads to reduced expression of three epa variable genes (B)

822 epaOX (upper), OG1RF_11714 (middle) and OG1RF_11710 (lower). The data are represented

823 as the fold change of normalized mRNA in comparison to wild type during both logarithmic (1 hr)

824 and stationary phase ( $4 \mathrm{hr}$ ) growth. The data show the average of three biological replicates \pm the

825 standard deviation. ${ }^{*} P<0.01,{ }^{* *} P<0.001$ by unpaired Student's t-test.

827 Figure 4. Emergence of phage resistance in E. faecalis mutL-Tn and mutS-Tn strain

828 backgrounds. (A) Culture density of $E$. faecalis mutL-Tn-E and mutS-Tn-E strains declined

829 similar to the wild type-E strain following VPE25 infection. However, VPE25 resistance gradually

830 emerged in the mutL-Tn-E and mutS-Tn-E strain backgrounds as indicated by an increase in cell

831 density following VPE25 infeciton. (B) mutL-Tn-E, mutS-Tn-E and wild type-E strains release

832 equivalent number of phages (PFU/ml) during the course of infection, and (C) grow similarly in

833 the absence of phage. Data are show the average of three biological replicates \pm the standard

834 deviation. (E, empty vector; $\mathrm{C}$, complemented). ${ }^{*} P<0.0001$ by two-way analysis of variance

835 (ANOVA).

837 Figure 5. Bacterial growth curve and one - step phage burst kinetics. (A) Optical density of

838 E. faecalis OG1RF cultures in the presence and absence of VPE25 infection $(\mathrm{MOI}=10)$. (B) One

839 - step VPE25 growth curve during the infection of E. faecalis OG1RF. The red arrows indicate

840 the time points selected for transcriptome analysis. Data from three independent experiments are

841 combined and presented as the mean with standard deviation. 
843 Figure 6. Global transcriptomic profile of $E$. faecalis OG1RF in response to VPE25. (A)

844 Hierarchical clustering of differentially expressed E. faecalis transcripts at 10, 20 and 40 minutes

845 post VPE25 infection in comparison to uninfected controls from each time point. R1 and R2

846 designate two independent biological replicates. The transcripts broadly cluster into early (green),

847 middle (blue), and late (magenta) expressed genes. (B) The profile plots of the early (top panel),

848 middle (central panel) and late (bottom panel) clusters are shown. Each line indicates a gene

849 within a cluster and the color intensity is calculated based on the distance from the center value

850 in that cluster.

Figure 7. Quantitative PCR confirms altered expression of bacterial quorum sensing and

853 T7SS genes during VPE25 infection. mRNA transcript levels of quorum sensing regulon genes,

854 including (A) fsr regulatory genes, (B) fsr - induced genes, and (C) fsr - repressed genes are

855 differentially expressed during VPE25 infection. (D) Progression of the lytic cycle induces the

856 expression of T7SS genes. Expression is the fold change relative to untreated samples at the

857 same time points. Data represent the average of three replicates \pm the standard deviation. ${ }^{*} P<$

$858 \quad 0.01$ to 0.0001 and ${ }^{* *} P<0.00001$ by unpaired Student's t-test.

Figure S1. Complementation restores phage sensitivity in OG1RF_10820, cscK and

OG1RF_12241 Tn mutants. (A) Introduction of the wild type allele but not the empty plasmid sensitizes E. faecalis Tn mutants to phage VPE25 infection. (B) Growth in the absence of VPE25 remains unaltered irrespective of the presence of the empty or complementation plasmid. (E, 864 empty vector; C, complemented).

Figure S2. Dampened viral gene expression and DNA replication aids in OG1RF_10820-Tn, 867 cscK-Tn and OG1RF_12241-Tn mutant tolerance to VPE25 infection. (A) Effect of various Tn 868 insertion mutations on VPE25 mRNA levels. The data are shown as the fold change of normalized 
mRNA in comparison to the wild type samples at various time points post-infection. (B) VPE25 DNA copy number calculated from an orf76 standard curve. Data are represented as average of

871 three replicates \pm the standard deviation. ${ }^{*} P<0.00001$ by unpaired Student's t-test.

873 Figure S3. The lytR gene does not influence the expression of epa core genes. Quantitative

874 PCR demonstrates equivalent mRNA levels of the epa genes epaA, epaE, and epaR in wild type 875 and the OG1RF_10820-Tn E. faecalis strains. The data are expressed as fold change of 876 normalized mRNA in comparison to the wild type at different time points and represent the 877 average of three biological replicates \pm the standard deviation.

Figure S4. Mutator strains facilitate the acquisition of VPE25 resistance. Growth of wild type, $\Delta$ pip, parent mutL-Tn, mutL-Tn colonies selected from THB plate without phage (mutL-TnNPh_C1 to C4 and mutS-Tn-NPh_C1 to C4) and those selected from VPE25 $\left(5 \times 10^{6}\right.$ PFU/ml) containing THB plates (mutL-Tn-Ph_C1 to C4 and mutS-Tn_C1 to C4) are shown (A and C) in the presence and (B and $\mathbf{D})$ in the absence of VPE25. The mutL-Tn and mutS-Tn colonies prewithout previous VPE25 challenge gained phage resistance during the course of infection. (E-F) All the mutL-Tn-Ph_C1 to C4 and mutS-Tn-Ph_C1 to C4have a defective VPE25 adsorption profile, while colonies selected from no phage plates are able to adsorb $\sim 70-80 \%$ of the phages 888 in the assay.

890 Figure S5. VPE25 modulation of E. faecalis genes during infection. (A) Euler diagram 891 representing the number of host transcripts with reduced abundance during phage infection. (B) 892 Among the 37 genes that are downregulated throughout the entire phage infection cycle, a large 893 percentage belong to ribosome biogenesis and translation. (C) Phage induced expression of 
894 multiple host transcripts include those involved in (D) DNA replication and repair, tRNA

895 biosynthesis and carbohydrate metabolism.

Figure S6. Transcriptomic profiling reveals alterations to phage and bacterial gene expression patterns throughout the course of infection. (A) Hierarchical clustering of differentially expressed VPE25 transcripts after 10, 20 and 40 minutes relative to 0 minutes post viral infection. 1 and 2 designate individual biological replicates. The transcripts are broadly

901 classified into early and late gene clusters depicted in purple and green, respectively. (B) Volcano

902 plots demonstrate changes in the gene expression pattern of $E$. faecalis OG1RF during VPE25

903 infection. Volcano plots highlight differentially expressed genes in the bacteria at 10 min (upper),

$90420 \mathrm{~min}$ (middle), and $40 \mathrm{~min}$ (bottom) post VPE25 infection. Downregulated genes are shown in

905 blue and upregulated genes are in red (fold change $>2, P<0.01$ ). (C) Phage NPV1 infection

906 downregulates fsr quorum sensing and upregulates T7SS in E. faecalis OG1RF. The Pip

907 independent phage NPV1 was used to query the expression of select fsr associated genes (fsrBD

908 and sprE) and type VII secretion genes (OG1RF_11100, OG1RF_11101, OG1RF_11104,

909 OG1RF_11105 and OG1RF_11115) by qPCR 1 hour after NPV1 infection of E. faecalis OG1RF.

910 The data are expressed as fold change of normalized mRNA in comparison to the uninfected

911 controls and represent an average of three biological replicates \pm the standard deviation. ${ }^{*} P<$

9120.0001 and ${ }^{* *} \mathrm{P}<0.00001$ by unpaired Student's t-test.

914 Table S1. Differentially abundant transposon mutants during VPE25 selection of the $E$. 915 faecalis OG1RF pooled Tn library.

917 Table S2. (A) Differential expression ratio of VPE25 genes during E. faecalis OG1RF 918 infection relative to the start of infection. (B) Differential expression ratio of $E$. faecalis 919 OG1RF genes during VPE25 infection relative to the untreated cultures. 
921 Table S3. (A) GO and KEGG annotations of enterococcal genes downregulated throughout

922 the course of VPE25 infection. (B) GO and KEGG annotations of enterococcal genes

923 upregulated during VPE25 infection.

924

925 Table S4. Bacterial strains, phages, plasmids and primers used in this study.

926 
A

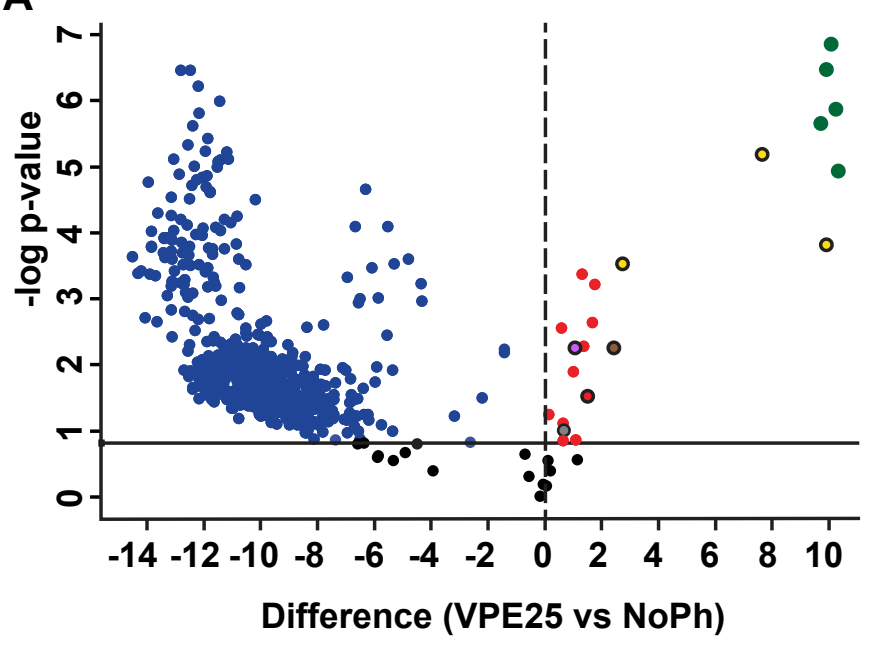

\begin{tabular}{|ll|}
\hline - pip $_{E F}-T n$ & ○ epa $-T n$ \\
○ OG1RF_12241 -Tn & $\circ$ OG1RF_10951 -Tn \\
○ OG1RF_10820-Tn & $\circ$ mutS -Tn \\
\hline
\end{tabular}

B

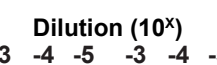

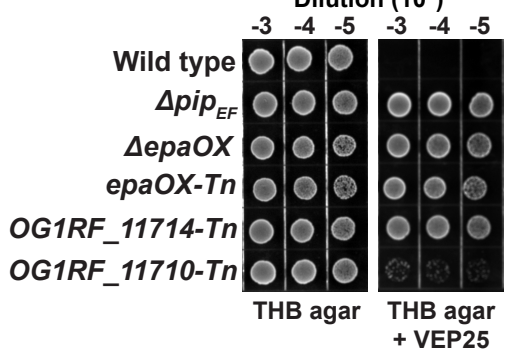

C

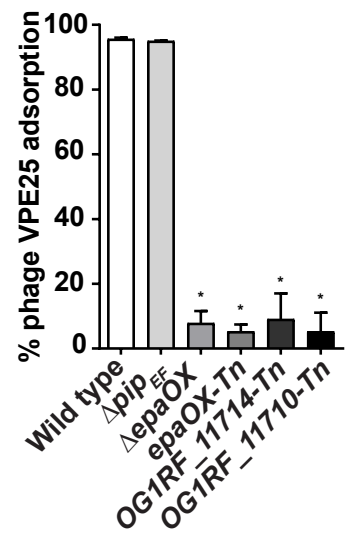

Fig. 1 
bioRxiv preprint doi: https://doi.org/10.1101/858506; this version posted November 29, 2019. The copyright holder for this preprint (which was not certified by peer review) is the author/funder, who has granted bioRxiv a license to display the preprint in perpetuity. It is made available under aCC-BY-NC-ND 4.0 International license.

A
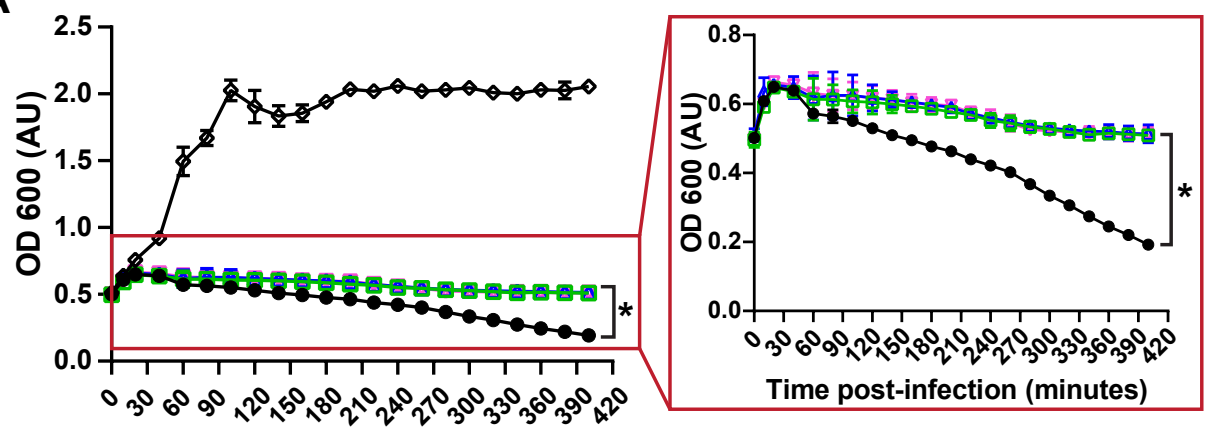

Time post-infection (minutes)

B

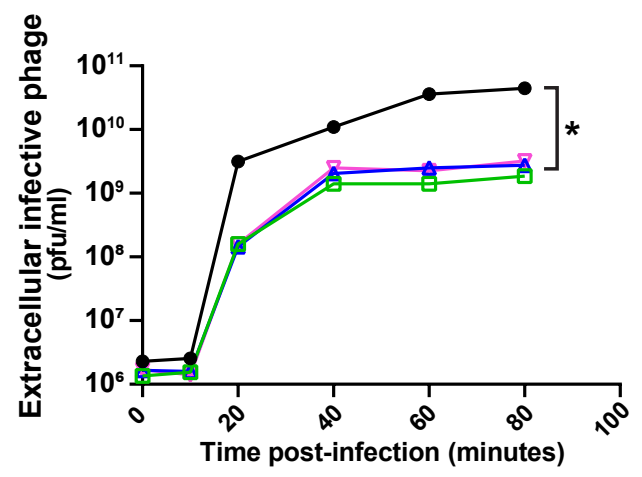

C

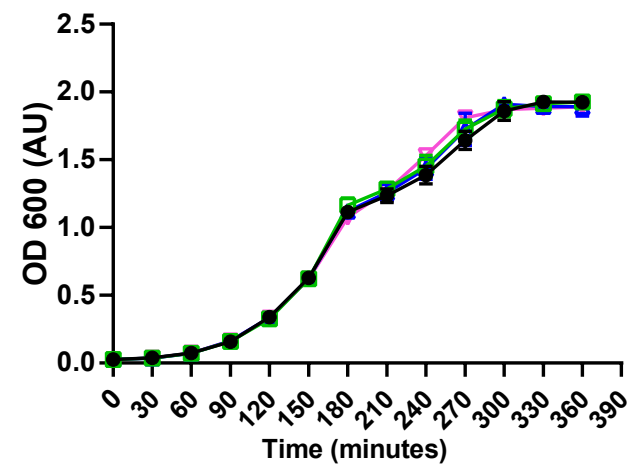

$\square$ OG1RF_10820-Tn

(LytR family response regulator)

$\nabla$ OG1RF_12241-Tn

(LysR family transcriptional regulator)

Fig. 2 

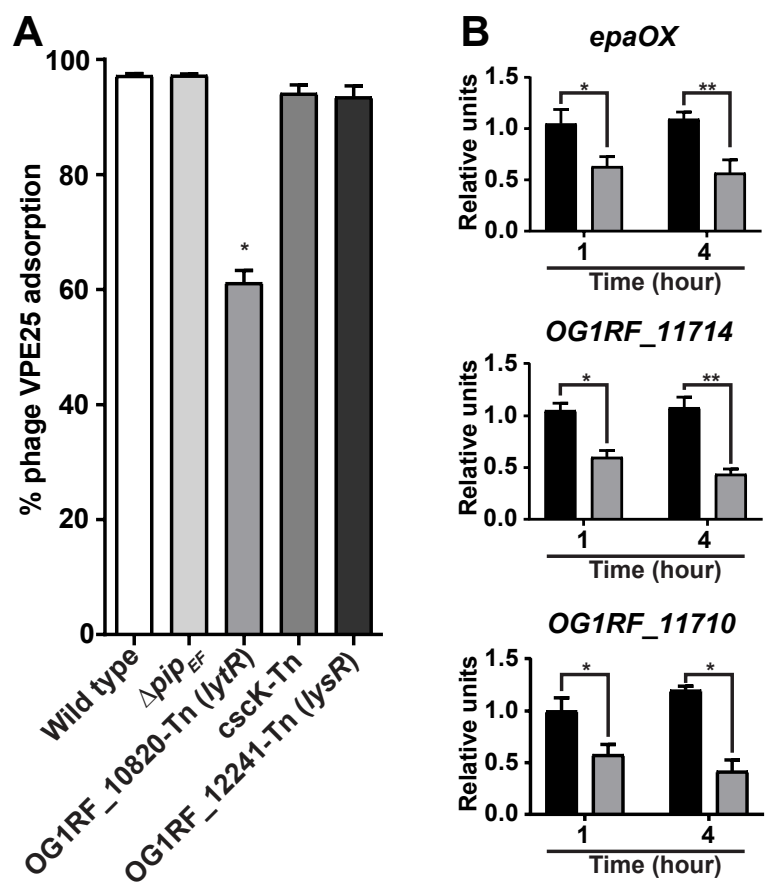

Wild type

OG1RF_10820-Tn (lytR)

Fig. 3 
A
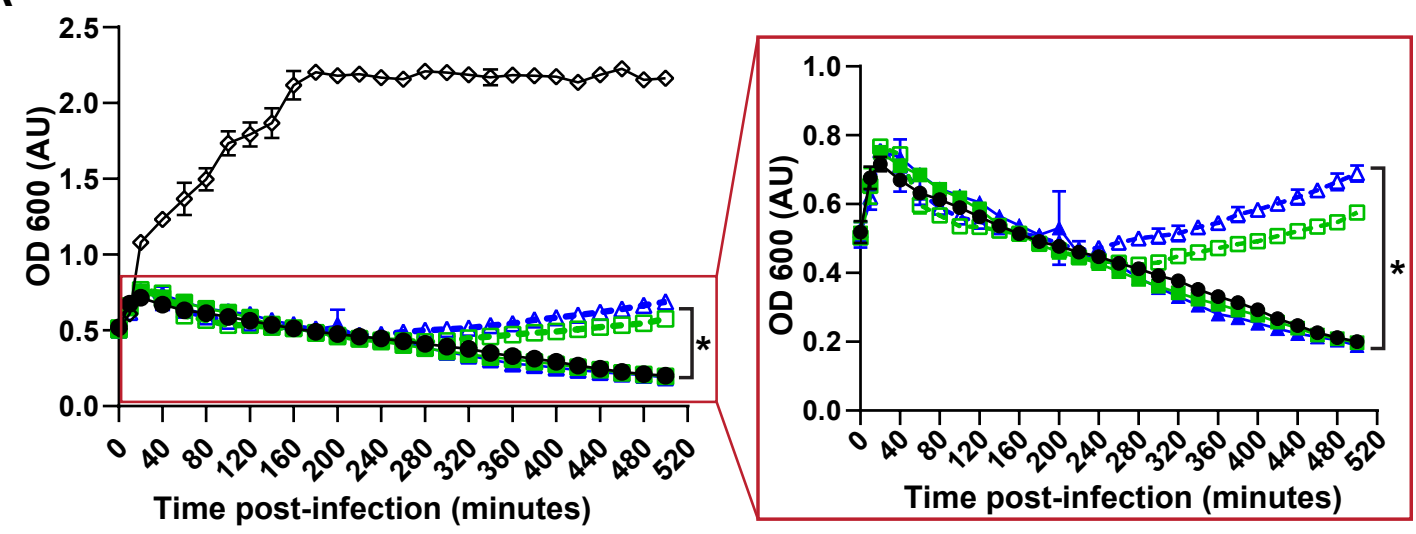

B

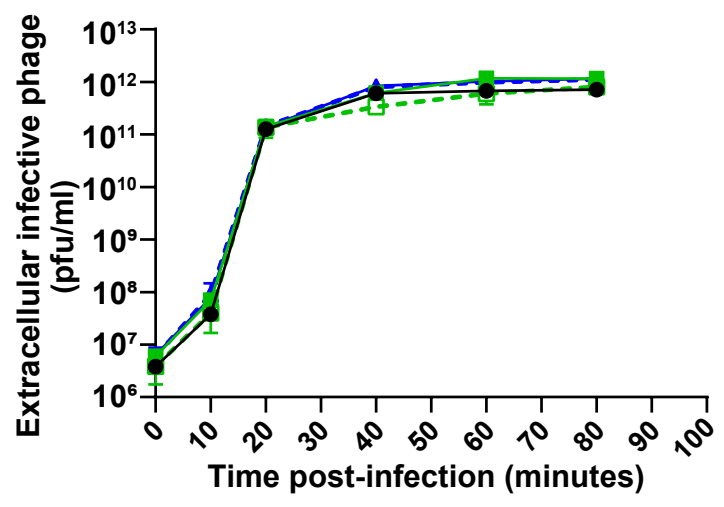

C

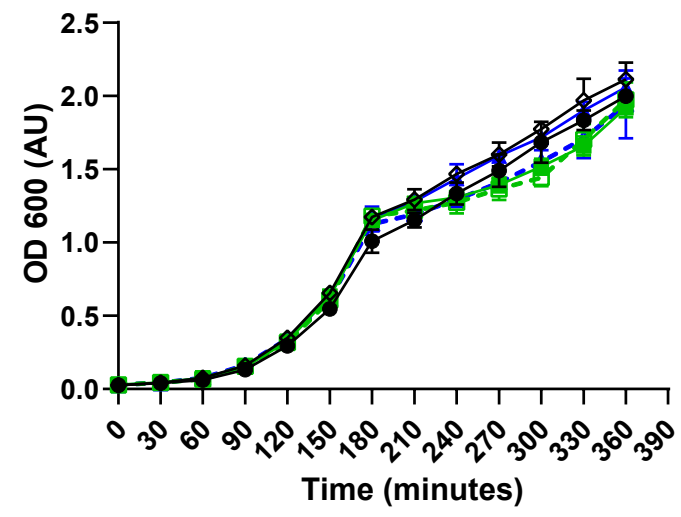

Fig. 4 
A

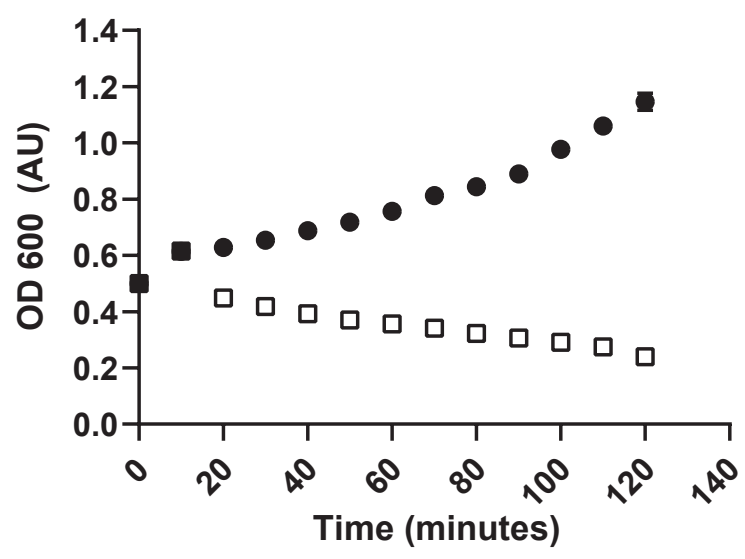

B

$$
\text { - OG1RF 口 OG1RF + VPE25 }
$$

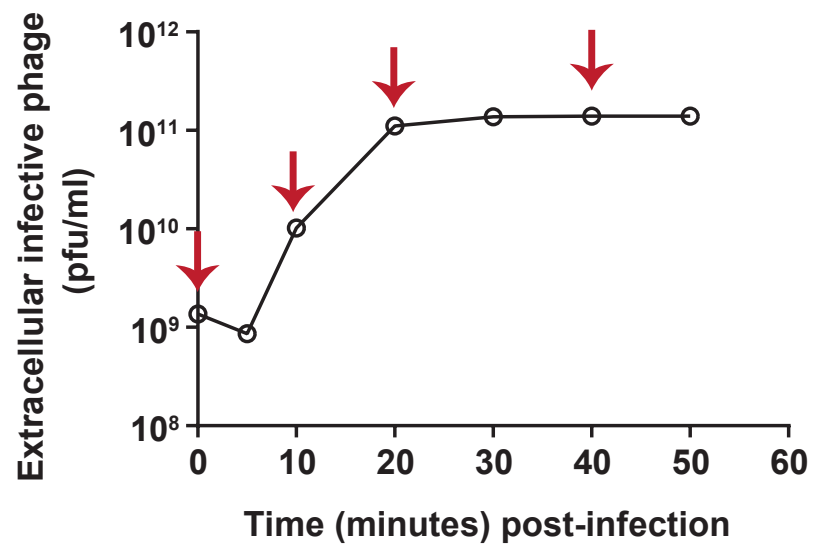

Fig. 5 
bioRxiv preprint doi: https://doi.org/10.1101/858506; this version posted November 29, 2019. The copyright holder for this preprint (which was not certified by peer review) is the author/funder, who has granted bioRxiv a license to display the preprint in perpetuity. It is made available under aCC-BY-NC-ND 4.0 International license.

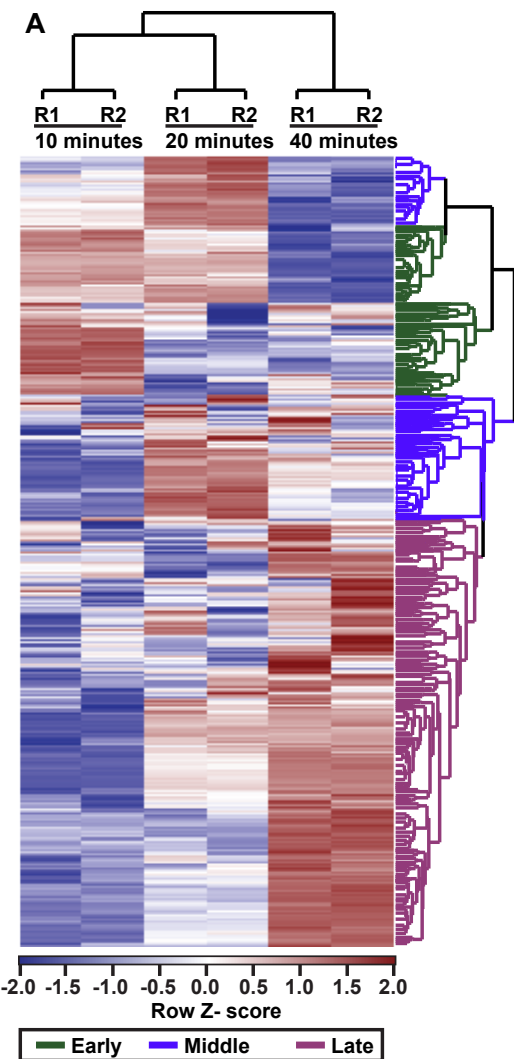

B
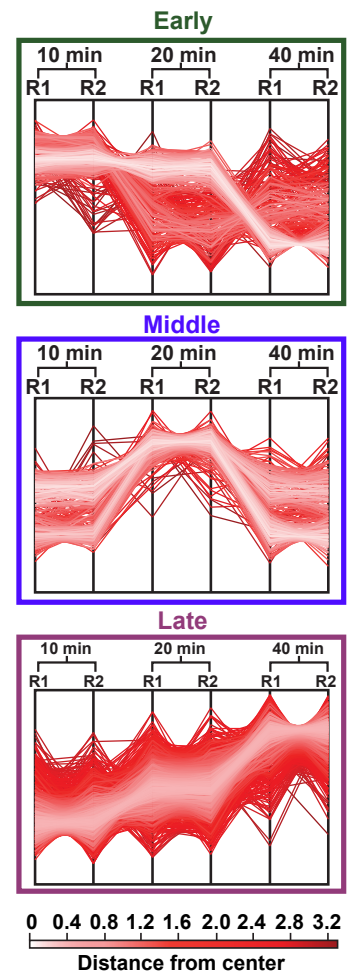

Fig. 6 
bioRxiv preprint doi: https://doi.org/10.1101/858506; this version posted November 29, 2019. The copyright holder for this preprint (which was not certified by peer review) is the author/funder, who has granted bioRxiv a license to display the preprint in perpetuity. It is made available under aCC-BY-NC-ND 4.0 International license.

A

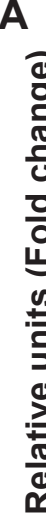

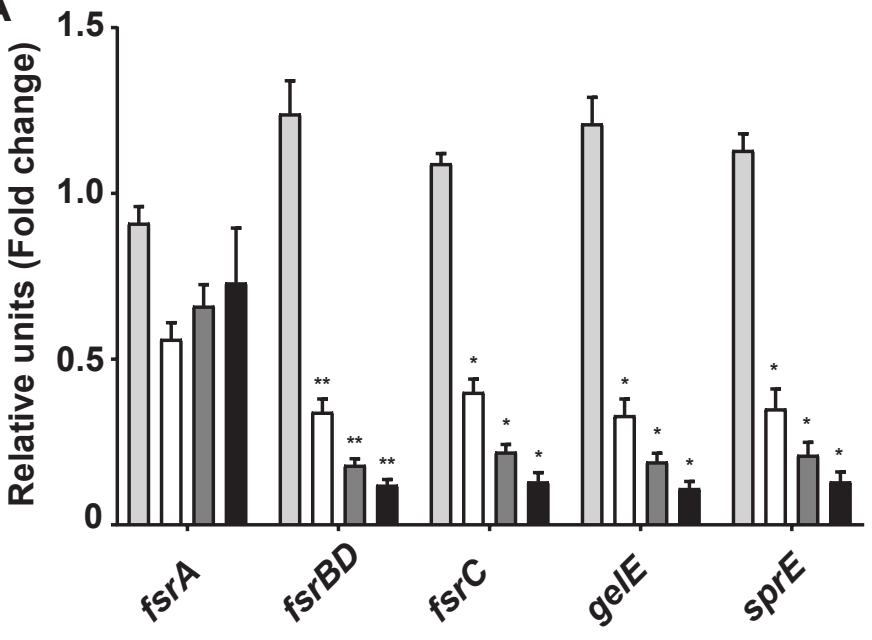

B

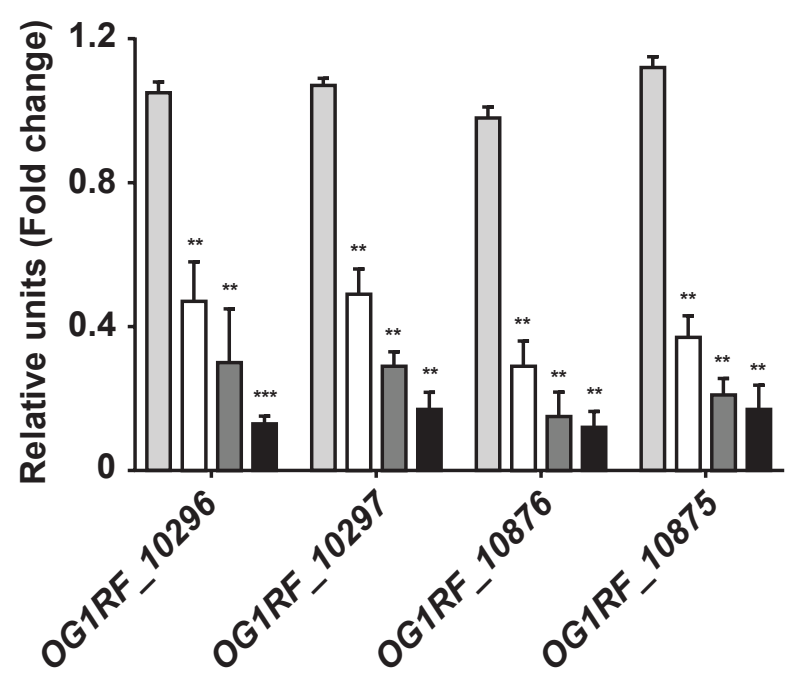

C

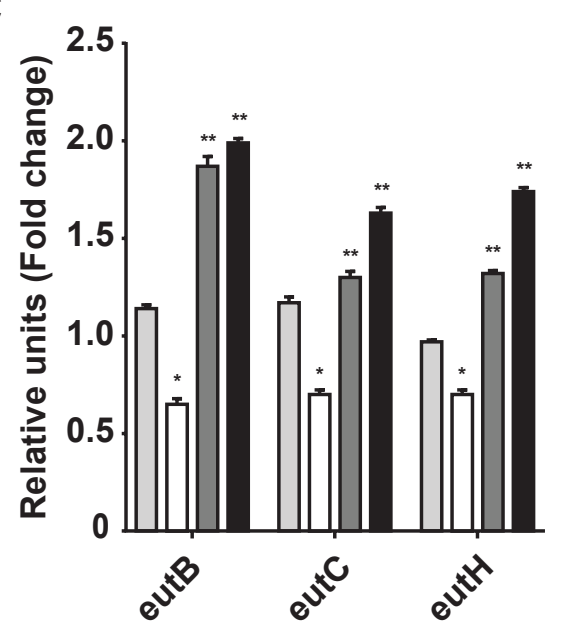

D

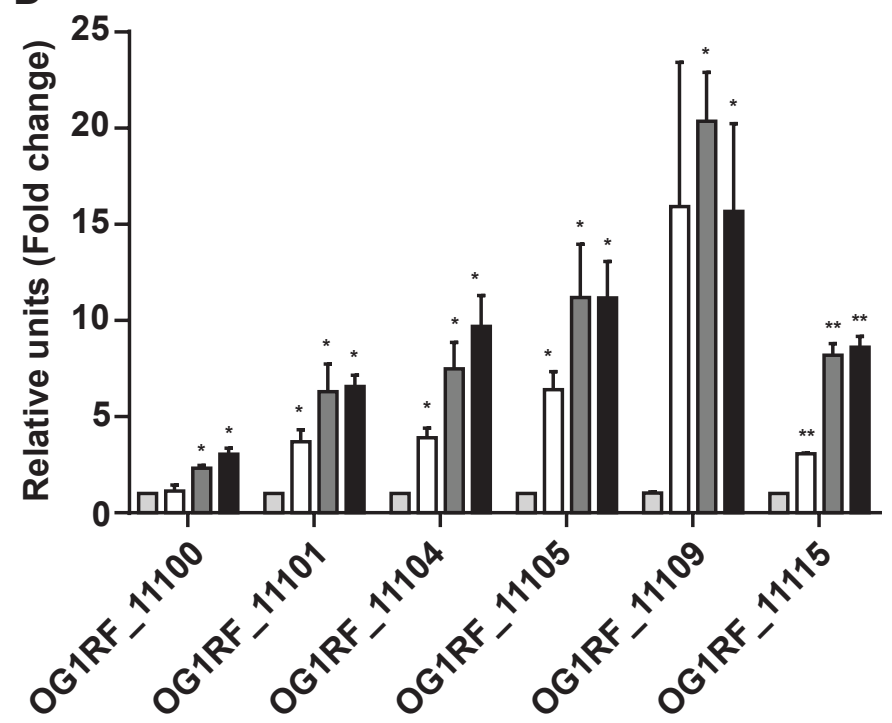

$\square 0 \min \square 10 \mathrm{~min} \square 20 \mathrm{~min} \square 40 \mathrm{~min}$

Fig. 7 
A

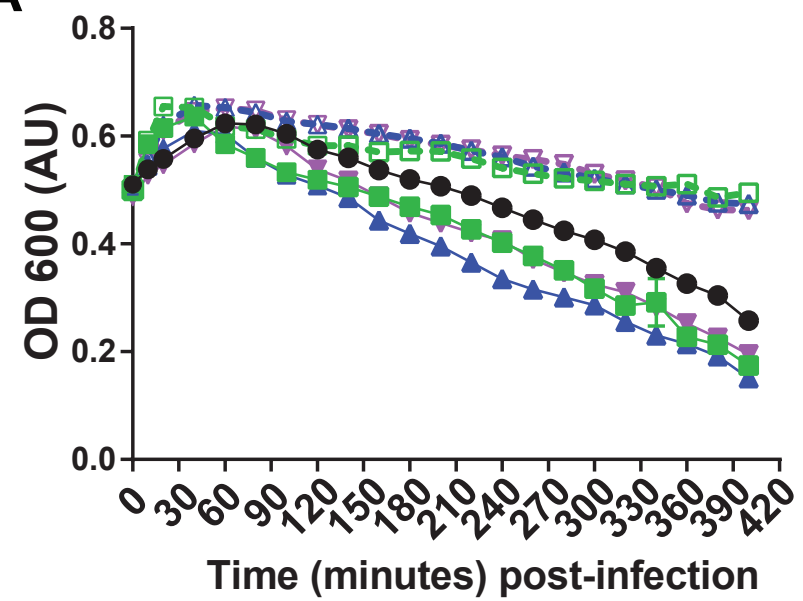

B

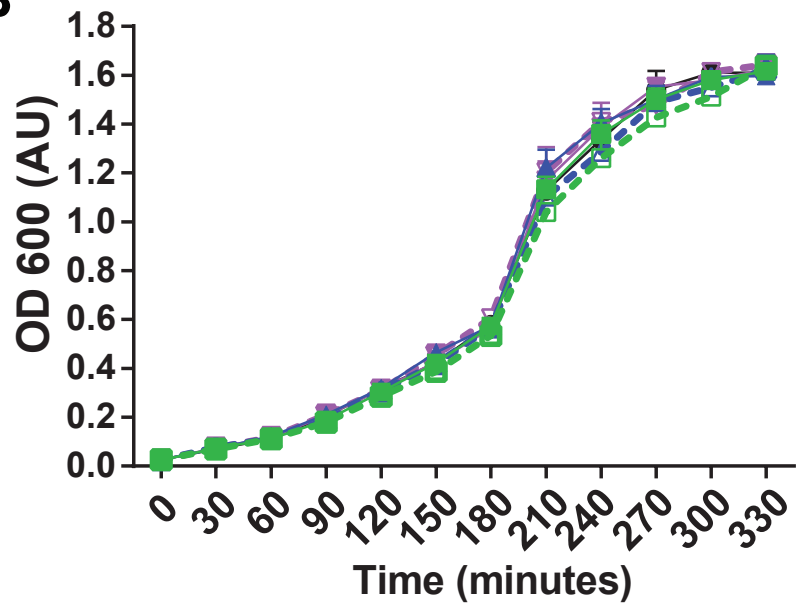



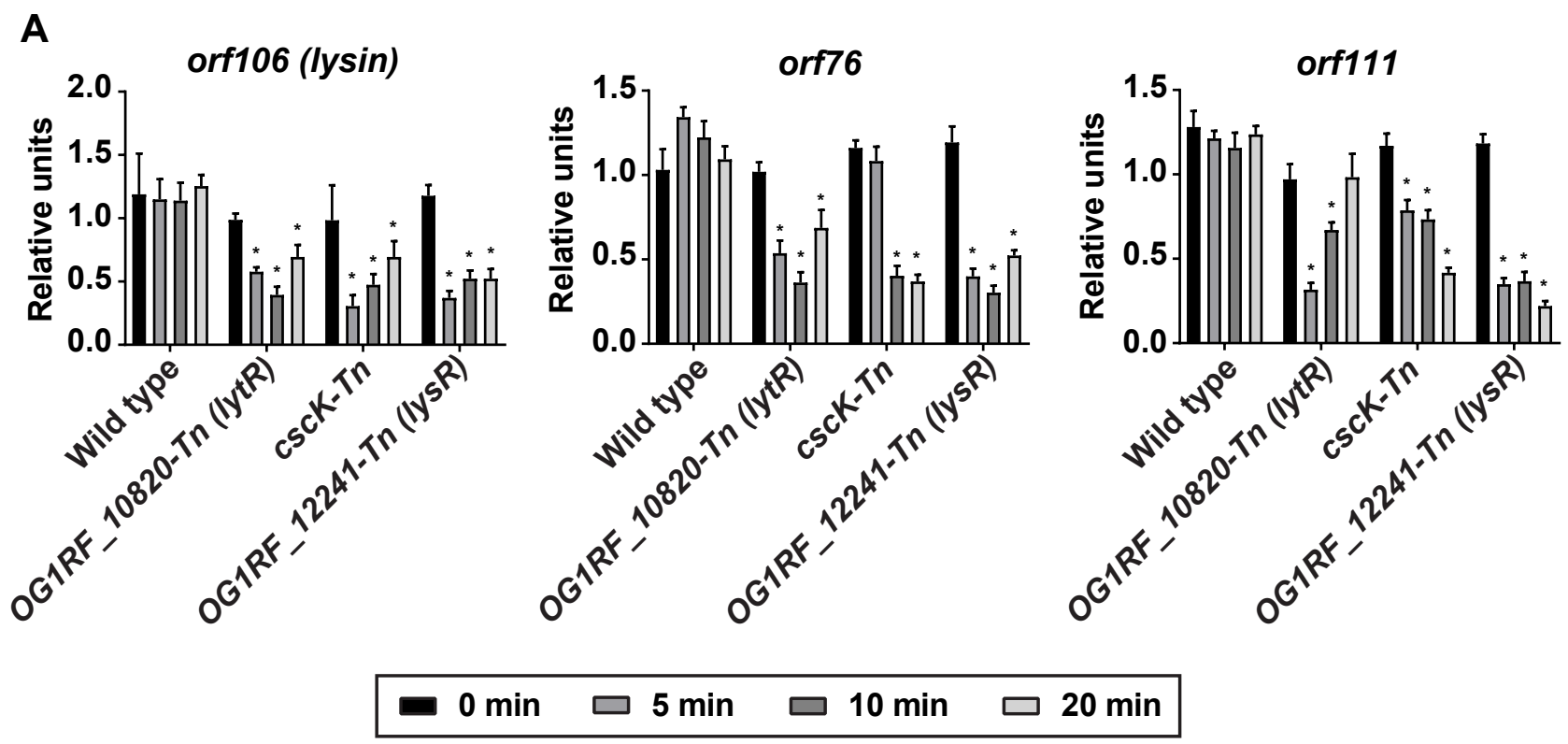

B

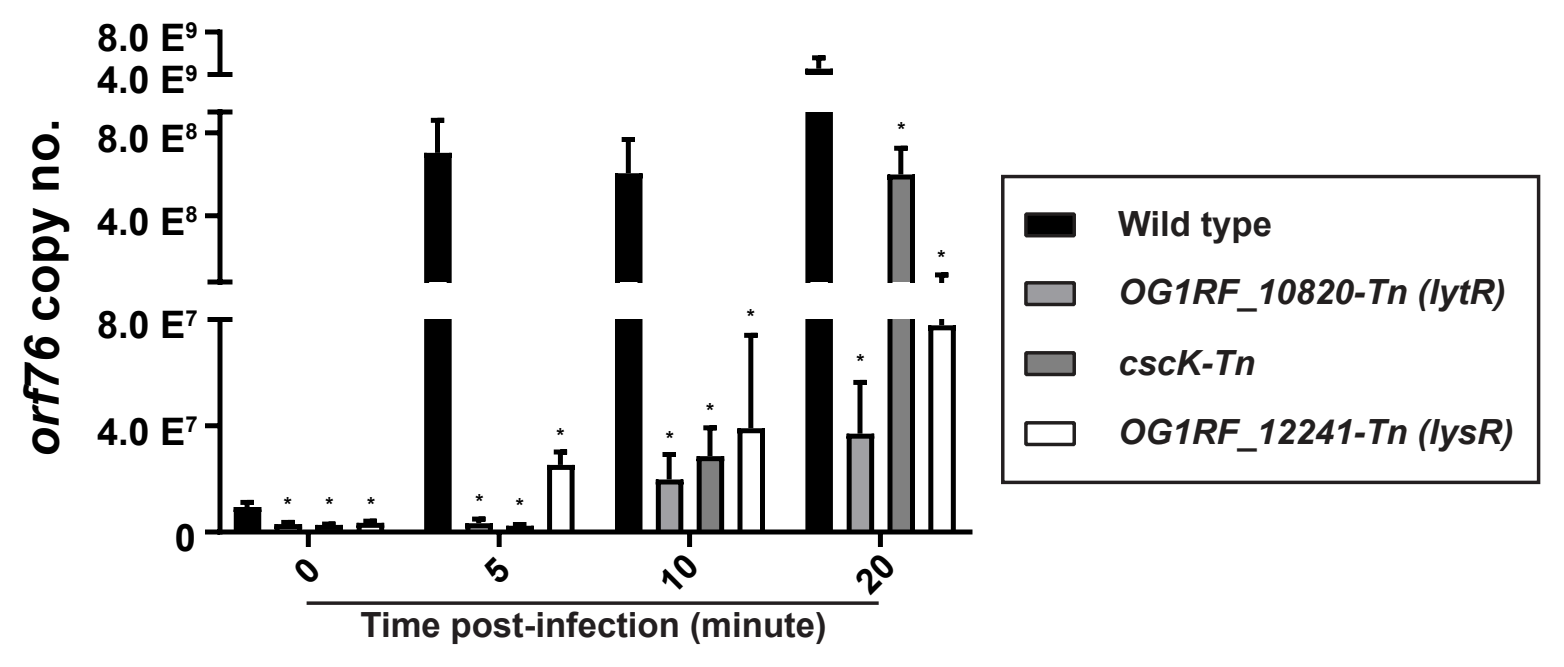

Supplementary Fig. 2 
bioRxiv preprint doi: https://doi.org/10.1101/858506; this version posted November 29, 2019. The copyright holder for this preprint (which was not certified by peer review) is the author/funder, who has granted bioRxiv a license to display the preprint in perpetuity. It is made available under aCC-BY-NC-ND 4.0 International license.
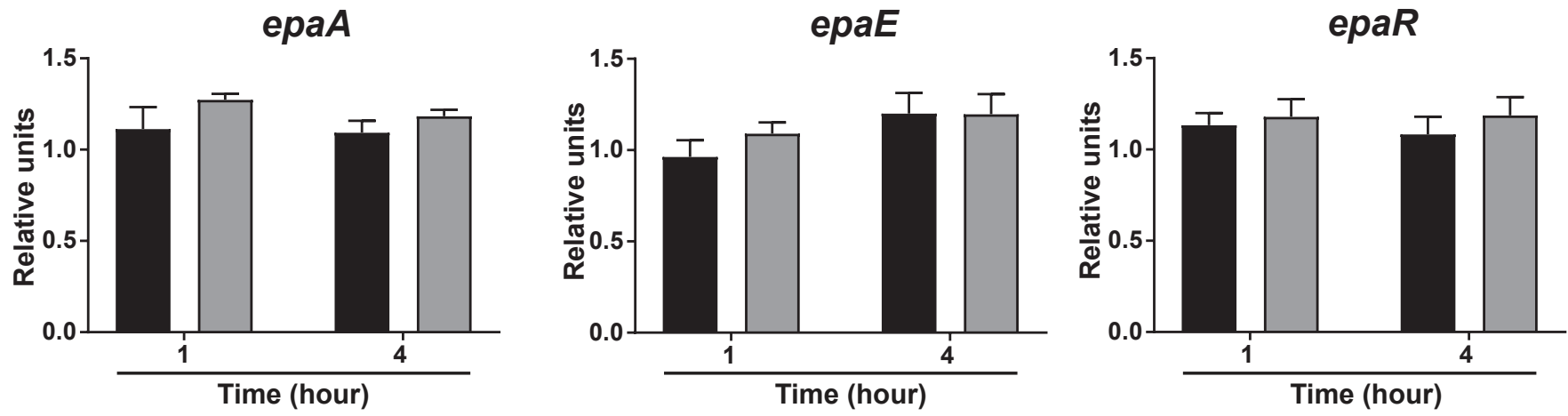

Wild type

OG1RF_10820-Tn (lytR)

Supplementary Fig. 3 
bioRxiv preprint doi: https://doi.org/10.1101/858506; this version posted November 29, 2019. The copyright holder for this preprint (which was not certified by peer review) is the author/funder, who has granted bioRxiv a license to display the preprint in perpetuity. It is made available under aCC-BY-NC-ND 4.0 International license.

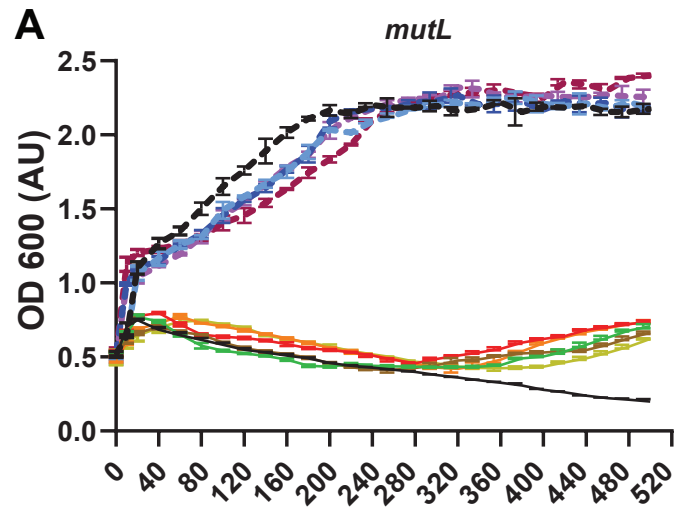

Time post-infection (minutes)

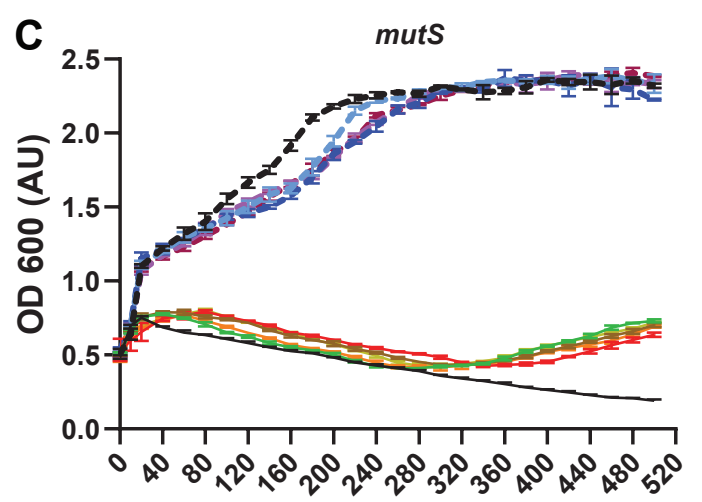

Time post-infection (minutes)

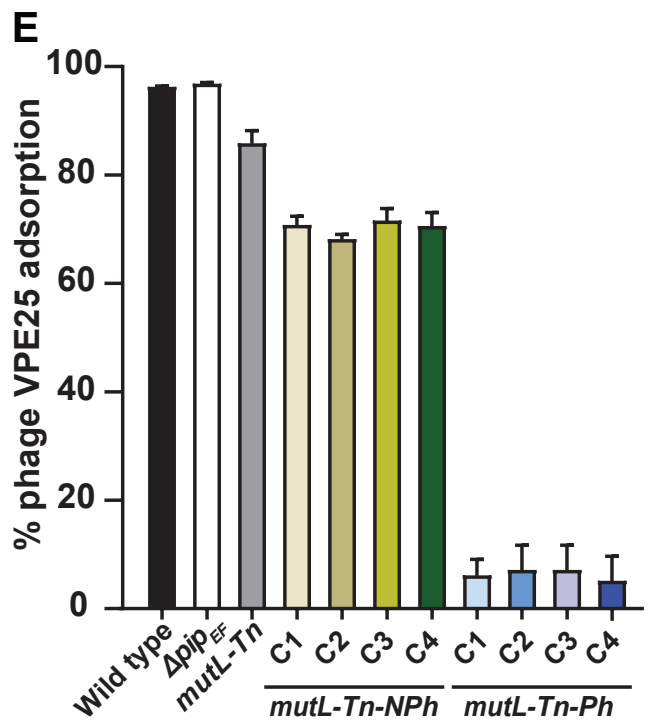

B

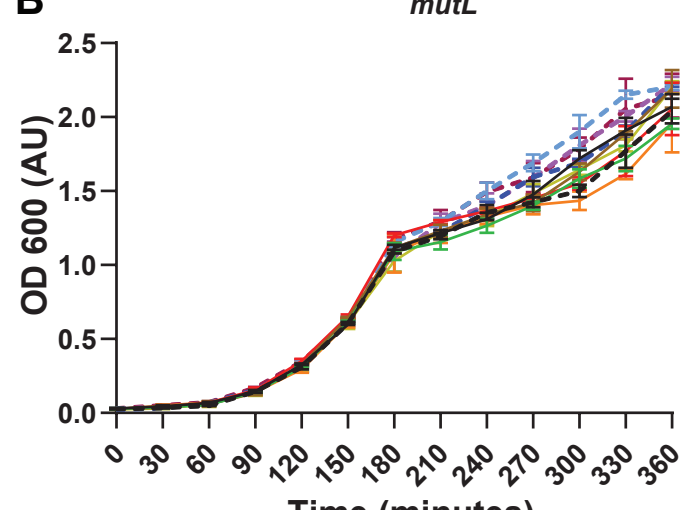

Time (minutes)

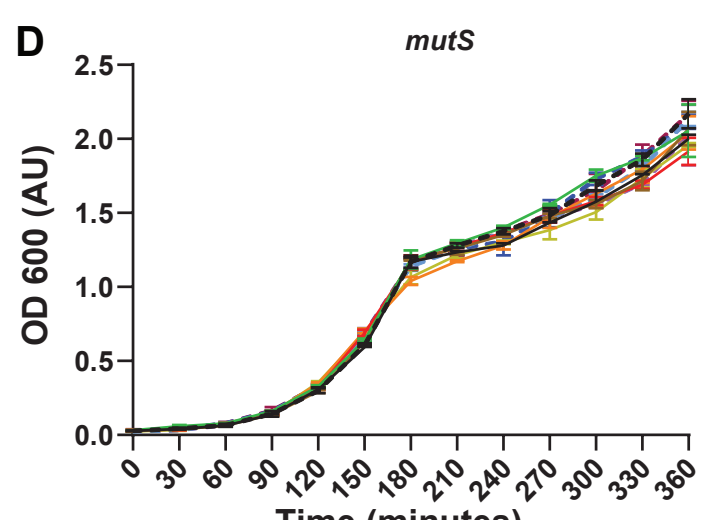

Time (minutes)

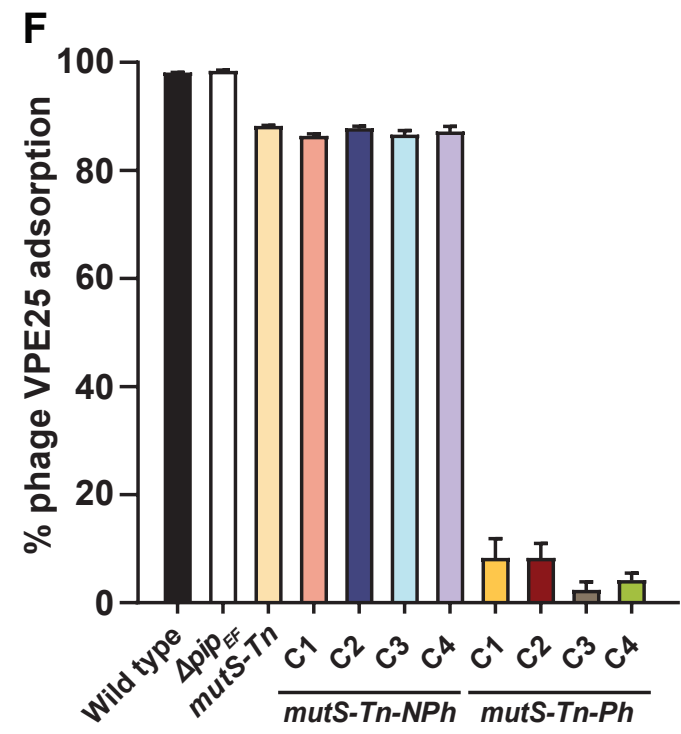

- Wild type

-. $\Delta p i p_{E F}$

- mutS-Tn

- mutS-Tn-NPh_C1

- mutS-Tn-NPh_C2

- mutS-Tn-NPh_C3

- mutS-Tn-NPh_C4

... mutS-Tn-Ph_C1

... mutS-Tn-Ph_C2

-.. mutS-Tn-Ph_C3

... mutS-Tn-Ph_C3

Supplementary Fig. 4 
A

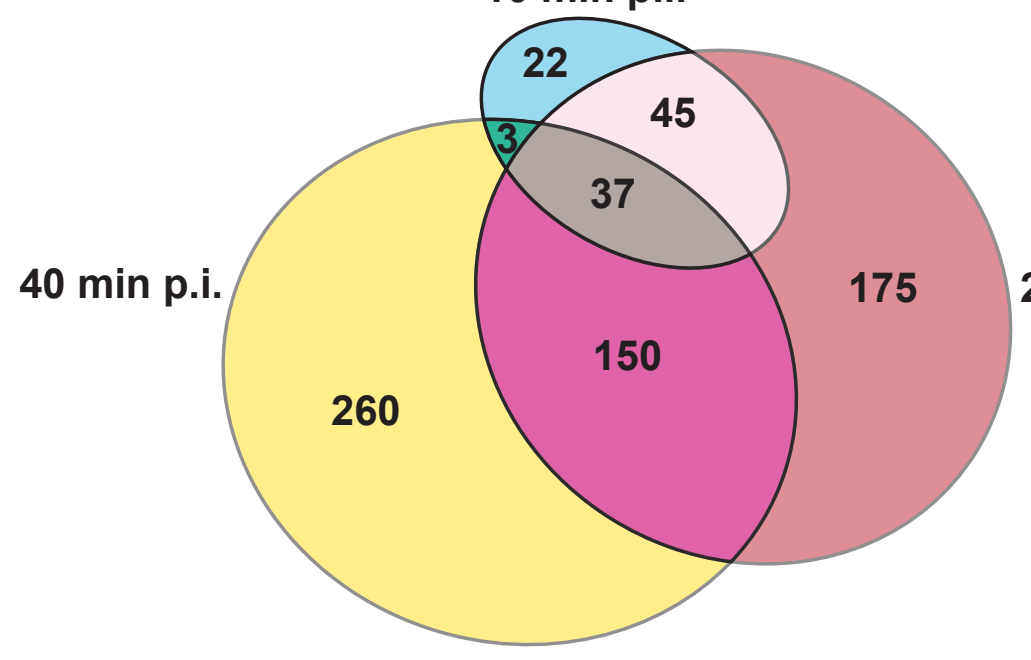

C

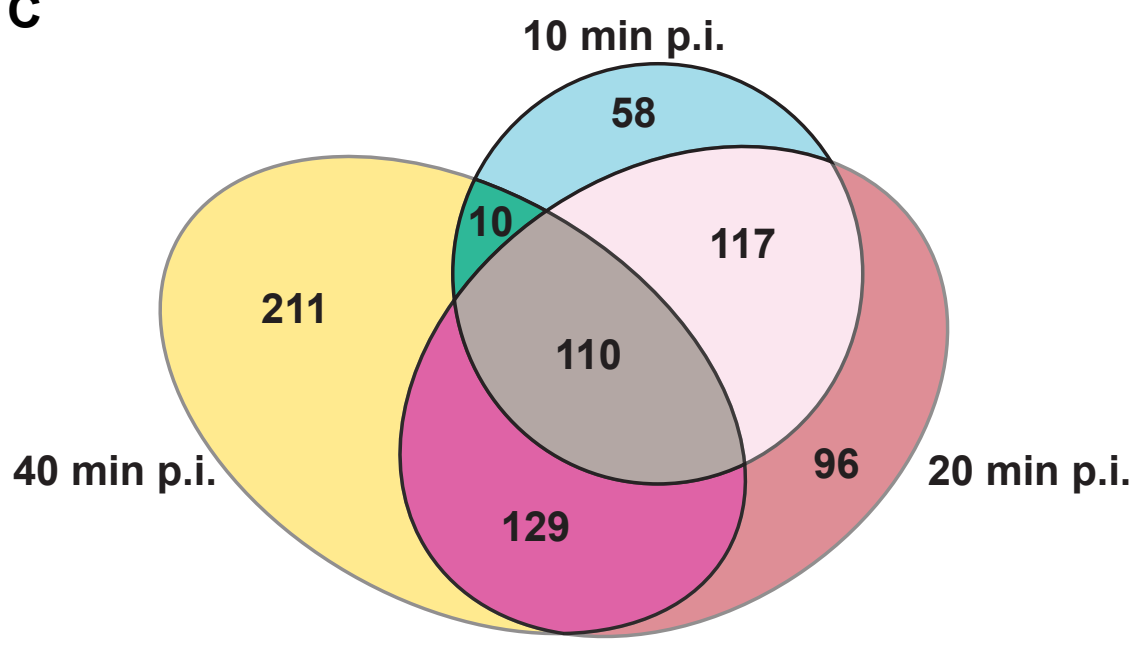

B

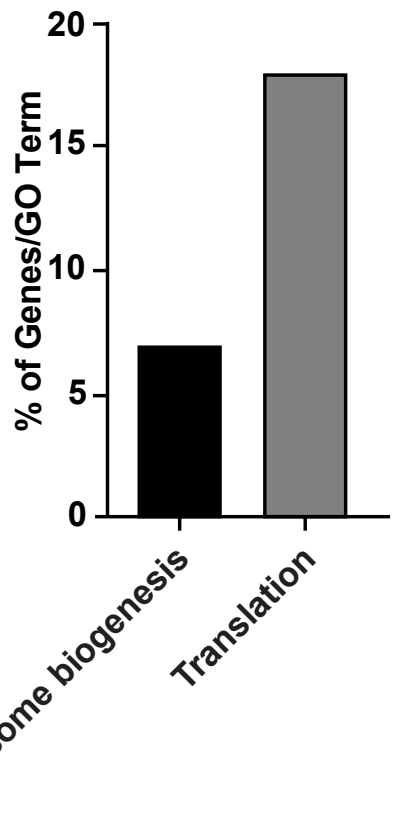

D

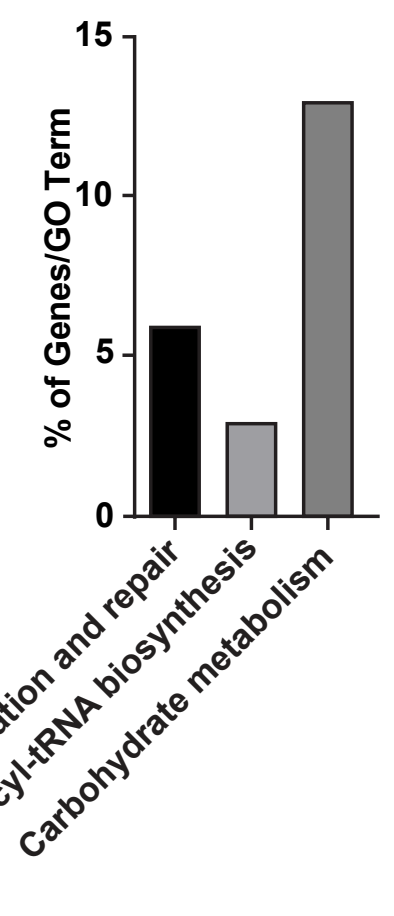


bioRxiv preprint doi: https://doi.org/10.1101/858506; this version posted November 29, 2019. The copyright holder for this preprint (which was not certified by peer review) is the author/funder, who has granted bioRxiv a license to display the preprint in perpetuity. It is made available under aCC-BY-NC-ND 4.0 International license.

A

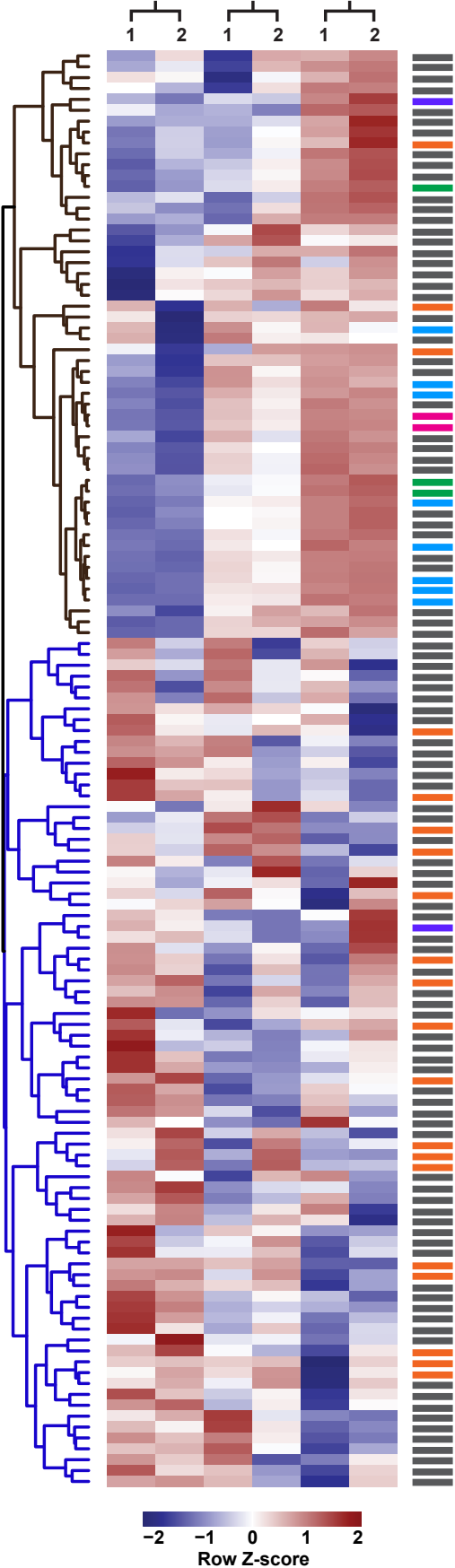

Hypothetical

Replication/Biosynthesis

DNA packaging

- Structural morphogenesis - Host cell lysis
B

Differentially expressed bacterial genes $10 \mathrm{~min}$. post-infection relative to the corresponding uninfected control

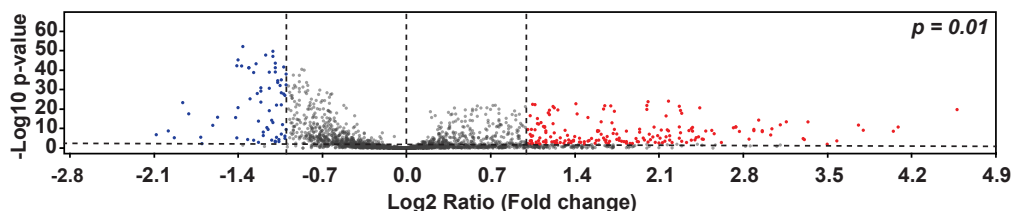

Differentially expressed bacterial genes $\mathbf{2 0}$ min. post-infection relative to the corresponding uninfected control

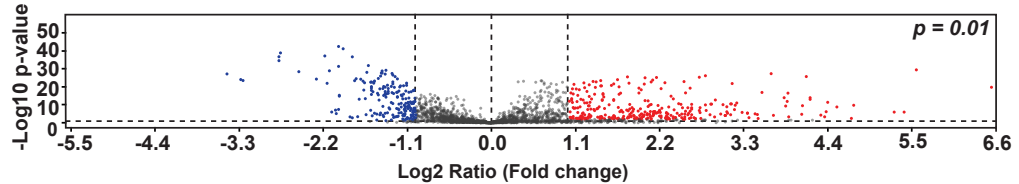

Differentially expressed bacterial genes $\mathbf{4 0} \mathrm{min}$. post-infection relative to the corresponding uninfected control

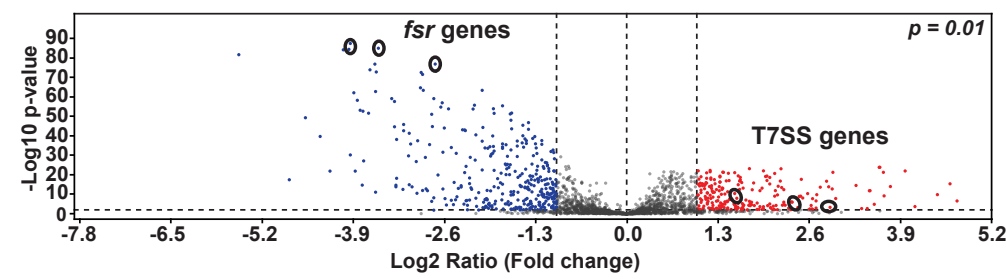

C

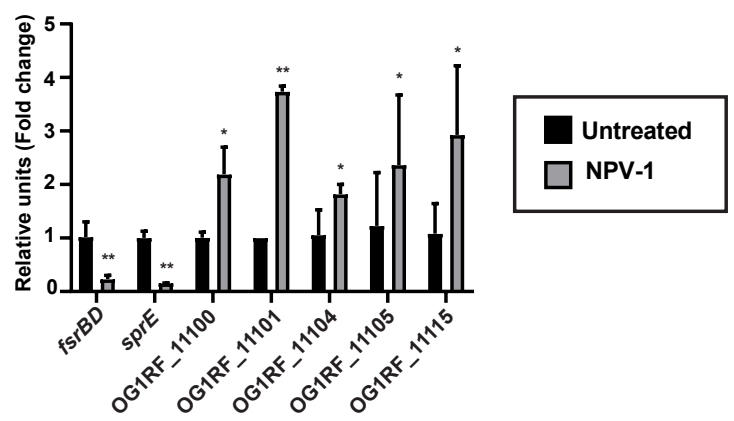

\section{Supplementary Fig. 6}

